\section{Vasijas Angosto Chico \\ Inciso: interacción entre quebradeños y yungueños. Evidencia petrográfica en secciones delgadas}

Fecha de recepción: 20/12/2018

Fecha de aceptación: 28/06/2019

\title{
Resumen
}

Desde su identificación a mediados del siglo XX, el estilo o complejo estilístico cerámico Angosto Chico Inciso (ACHI) generó continuos interrogantes sobre su origen, su distribución geográfica, consumo diferencial e identidad. En estas páginas, como resultado del análisis petrográfico de las pastas de cuarenta y una vasijas ACHI aportamos información potencialmente útil para responder algunos de estos interrogantes. Se presenta un breve panorama de la historia en los estudios de estas cerámicas y se comenta la contribución de la perspectiva arqueométrica aplicada en la interpretación social de las diferentes elecciones tecnológicas registradas.

\section{Angosto Chico Inciso Vessels: Interaction and integration between quebradeños and yungueños. Petrographic evidence inthin sections}

\begin{abstract}
Since its identification in the middle of the $\mathrm{XX}^{\text {th }}$ century, the Angosto Chico Inciso (ACHI) style or stylistic complex generated continuous questions about its origin, geographical distribution, differential consumption and identity. In these pages, the results of the petrographic analysis applied to the pastes of $41 \mathrm{ACHI}$ vessels provide potentially useful information to answer some of these questions. A brief overview about the history in the studies of these ceramics is presented so as the contribution of the archaeometric perspective in the social interpretation of the different technological choices recorded is commented.
\end{abstract}

Palabras clave

Quebrada de Humahuaca Angosto Chico Inciso Caracterizaciones petrográficas Agencialidad

\section{Keywords}

Quebrada de Humahuaca Angosto Chico Inciso Petrographic characterizations Agency 
Mots clés

Quebrada de Humahuaca Angosto Chico Inciso Caractérisations pétrographiques Agence

\section{Pots Angosto Chico Inciso : l'interaction et l'intégration entre que- bradeños et yungueños. Évidence pétrographique sur des lames minces}

\section{Résumé}

Depuis son identification au milieu du XXeme siècle, le style ou le complex estylistique connu comme Angosto Chico Inciso (ACHI) a posé plusieures questions à propos de son origine, sa distribution géographique, sa consommation différentielle et son identité. Dans ces pages, à partir de l'analyse pétrographique des pâtes de 41 poteries ACHI fournissent des informations potentiellement utiles pour répondre à certaines de ces questions. On présente un bref aperçu de l'histoire des études de ces céramiques et l'on commente la contribution de la perspective archéométrique appliquée à l'interprétation sociale des différents choix technologiques.

\section{Introducción}

A las vasijas Angosto Chico Inciso (en adelante ACHI) - predominantemente ollas y en menor cantidad botellones o cántaros- se les asignó un probable origen oriental (Selvas Occidentales o Chaco). Ello se sustentaba en el tratamiento decorativo por desplazamiento de pasta (incisiones más o menos ordenadas en los cuellos y eventuales aditamentos modelados), técnica decorativa que se diferenciaba claramente de la tradición local Humahuaca (Figura 1).

La tradición alfarera de la quebrada de Humahuaca para momentos prehispánicos tardíos se manifiesta en un estilo regional predominante, caracterizado por vasijas pintadas con motivos geométricos negros sobre engobe rojo, marcando diferencias de identidad respecto de otros estilos regionales del Noroeste argentino (Santamariano, Belén, Famabalasto, Yavi-Chicha, etc.). Siempre nos preguntamos cuáles habrían sido los procesos y situaciones sociales que habrían generado la coexistencia de dos estilos tan disímiles a lo largo de la quebrada de Humahuaca: el Humahuaca Negro sobre Rojo - con su versión posterior modificada: Humahuaca Inca- y el ACHI que conforma un universo de vasijas domésticas diferente.

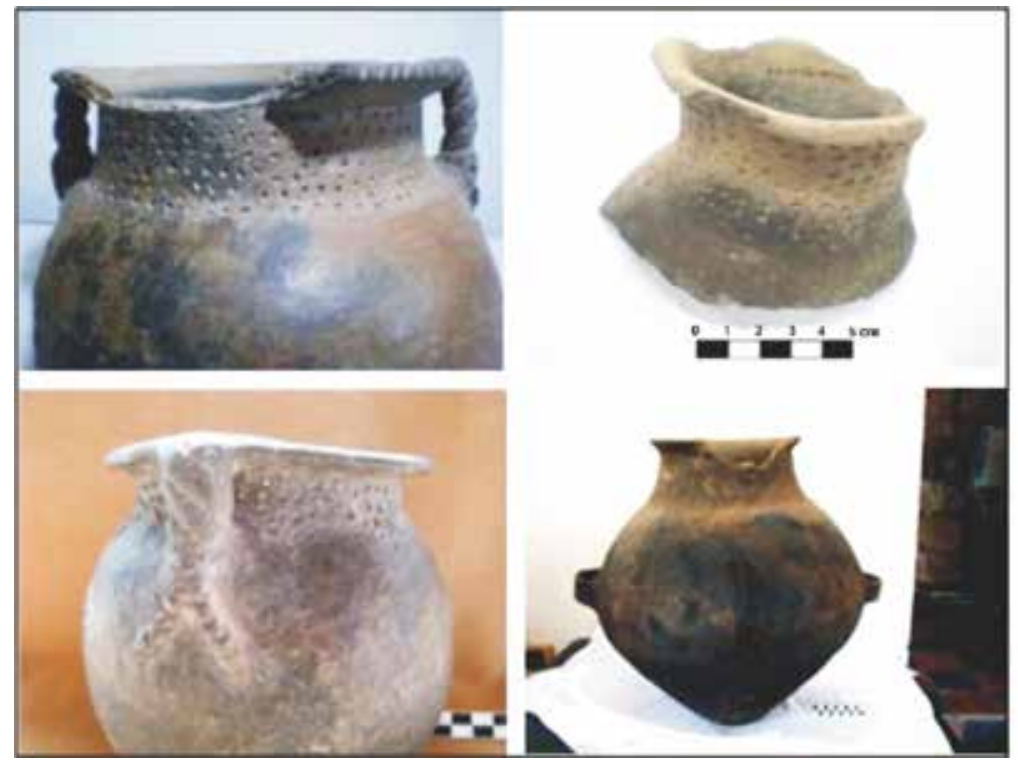

Figura 1. Algunos ejemplo de vasijas Angosto Chico Inciso recuperadas en la quebrada de Humahuaca (Pucara de Volcán, Esquina de Huajra y Pucara de 
En la descripción de los materiales excavados en Ciénaga Grande, Salas (1945) advierte la peculiar decoración en banda con pequeñas incisiones ordenadas en el cuello de una vasija completa y en cinco fragmentos con asas retorcidas. Posteriormente, Bennett $e t$ al., en la recopilación de las diferentes modalidades alfareras presentes en la quebrada de Humahuaca (1948), resumen otras referencias dispersas de estas alfarerías (Casanova, 1942; Gatto, 1946) proponiendo un dudoso estilo que denomina Angosto Chico Inciso (nombre de un sitio ubicado al norte del Pucara de Tilcara). En su descripción, además de las características incisiones punteadas en los cuellos, incluyen otros rasgos como las incisiones de guiones, unguiculados y entrecruzados. Hoy consideramos que los últimos se separan del estilo ACHI, especialmente los entrecruzados que corresponden a vasijas más tempranas (Formativo), como las ilustradas por Debenedetti (1910: figuras 93 y 97) procedentes de La Isla.

En la década de 1960, Madrazo realizó una revisión del ACHI, al que consideró un Complejo, en tanto lo definió como "una entidad poco homogénea" (Madrazo, 1970: 24) que incluía varios estilos, presentando una amplia variedad de motivos y una distribución desigual en la quebrada de Humahuaca. Asimismo, propuso que el Angosto Chico Inciso tendría sus orígenes en la zona del Chaco, afirmando que su cronología sería contemporánea a la del estilo Tilcara Negro sobre Rojo, teniendo una introducción tardía en el ámbito quebradeño (Período de Desarrollos Regionales) y que perduraría hasta momentos incaicos e incluso hasta la época colonial. Como ejemplo de perduración, registramos reminiscencias del $\mathrm{ACHI}$ en vasijas etnográficas chaqueñas como la ilustrada por Nordenskiöld (1903: figura 9). Recién en la década de 1990 Ottonello (1994) retoma la hipótesis de su origen oriental y reafirma una cronología tardía para esta modalidad en la Quebrada. Ottonello ensaya una sistematización de las variantes morfológicas del ACHI, considerando a las vasijas que integran la colección del Pucara de Volcán (sector centro-sur de la quebrada de Humahuaca), que está depositada en el Museo Etnográfico de la Facultad de Filosofía y Letras de la Universidad de Buenos Aires.

En el transcurso de nuestros estudios arqueométricos y tipológicos de la cerámica de la quebrada de Humahuaca (Cremonte, 1990, 1992, 1994, 2006) pudimos definir diferentes tipos de pastas. Los primeros estudios de las pastas ACHI se incluyeron en la clasificación en lupa binocular de todos los tipos y estilos cerámicos de la quebrada de Humahuaca registrados en el marco de los Proyectos CONICET dirigidos por Tarragó y Madrazo $(1985,1995)$.

En esa clasificación en lupa binocular definimos el estándar 13 con pizarras y filitas como la pasta más común en las vasijas $\mathrm{ACHI}$ con sus variantes (A, no oxidada como la más frecuente y B, oxidada). Luego se identificaron las variantes $13 \mathrm{C}, 13 \mathrm{D}$ con abundantes inclusiones vítreas y el estándar 33 de textura laminar, de cocción oxidante con núcleo gris e inclusiones grises angulosas (Cremonte, 1992). Los primeros análisis petrográficos en secciones delgadas (Cremonte, 1989: m.s.) permitieron unificar las variantes Ay B como un mismo tipo de pasta y desestimar el estándar 33 por no reiterarse en las muestras agregadas; pasta que quedó subsumida en el estándar 13AB. Por otro lado, similitudes observadas entre el estándar $13 \mathrm{AB}$ y las pastas de otras vasijas lisas ordinarias junto con otras características de las vasijas ACHI, llevaron a plantear que:

La popularidad, características de manufactura y tamaños de las piezas Angosto Chico, que se vienen reiterando en todos los sitios tardíos del área de estudio, plantean su producción local. Considero que el hecho de ser más populares en sectores orientales no justifica interpretarlas como alóctonas. Este solo sería el caso, hasta ahora, para algunas piezas pequeñas con diferentes componentes de pasta que, sugestivamente, son comunes en sitios más meridionales (como estamos viendo para Hornillos, Volcán y Tiraxi). (Cremonte, 1994: 181) 
Ya para ese entonces, una muestra de sedimento arcilloso recuperado en las excavaciones de la Unidad 1 del Pucara de Tilcara, analizada mediante DRX, presentaba fuertes afinidades mineralógicas con una pasta $\mathrm{ACHI}$ de la variedad $13 \mathrm{AB}$, pudiendo ser una potencial materia prima local usada en la manufactura de esas vasijas, comunes en el Pucara. Esta evidencia sustentaba la hipótesis de que al menos un porcentaje importante del ACHI hallado en sitios de la quebrada de Humahuaca fuera de manufactura local. Las pastas con estándares 13C y 13D indicaron una situación diferente. Para el área de Tilcara, los componentes petrográficos de las mismas - abundante cuarzo y feldespato potásico (11 a 27\%), cuarcitas y/o litoclastos de granito y eventual presencia de tiesto molido- indicaba que eran similares a pastas ACHI, Corrugadas, Alisadas y Ordinarias del área de Volcán y de sitios de la cuenca Tiraxi-Tesorero. Estas pastas eran muy raras en el sector central de la quebrada de Humahuaca y correspondían a vasijas pequeñas, indicando que se trataba de manufacturas no locales (Cremonte, 2006).

Actualmente, como continuación y ampliación del aporte de Ottonello (op. cit. 1994) advertimos un entramado de variables de pastas, formas y diseños que permitirían diferenciar conjuntos de vasijas ACHI no locales, pero también otros que podrían ser de producción local, apareciendo en un mismo contexto doméstico. Nos preguntamos entonces ¿qué amplitud espacial y temporal tienen estas variaciones? ¿Cuáles elecciones tecnológicas serían propias de la quebrada de Humahuaca y cuáles de las yungas ${ }^{1}$ ?

\section{Metodología y muestra analizada}

El estudio realizado se enmarca en el concepto de elecciones tecnológicas (Letchman, 1977), considerando que las acciones tecnológicas son posibilidades seleccionadas y aceptadas grupalmente que reflejan relaciones sociales. Las comunidades de práctica involucradas en las maneras de hacer un estilo cerámico reflejarán continuidades y rupturas, permanencias, cambios y resignificaciones respecto de sus conocimientos tradicionales. Además no debemos soslayar el rol del estilo, como reflejo de identidades $y$ dinámicas sociales que pueden ser detectadas mediante el análisis de sus patrones de variación y de consumo. Desde esta perspectiva, en esta oportunidad nos referiremos al aporte del análisis tecnológico de las pastas mediante sus caracterizaciones petrográficas cuali-cuantitativas en secciones delgadas.

Figura 2. Mapa de los sectores centrales y meridionales de la quebrada de Humahuaca con sus valles orientales adyacentes (Valle Grande) y sitios de la cuenca Tiraxi-Tesorero: AP 1 (Álvarez Prado), OCLO (Cucho de Ocloyas) y AT (Antigal de Tacana). Círculo Mayor: área de distribución del ACHI. Círculo menor: área con sector de mayor concentración de ACHI. Fuente: Google.

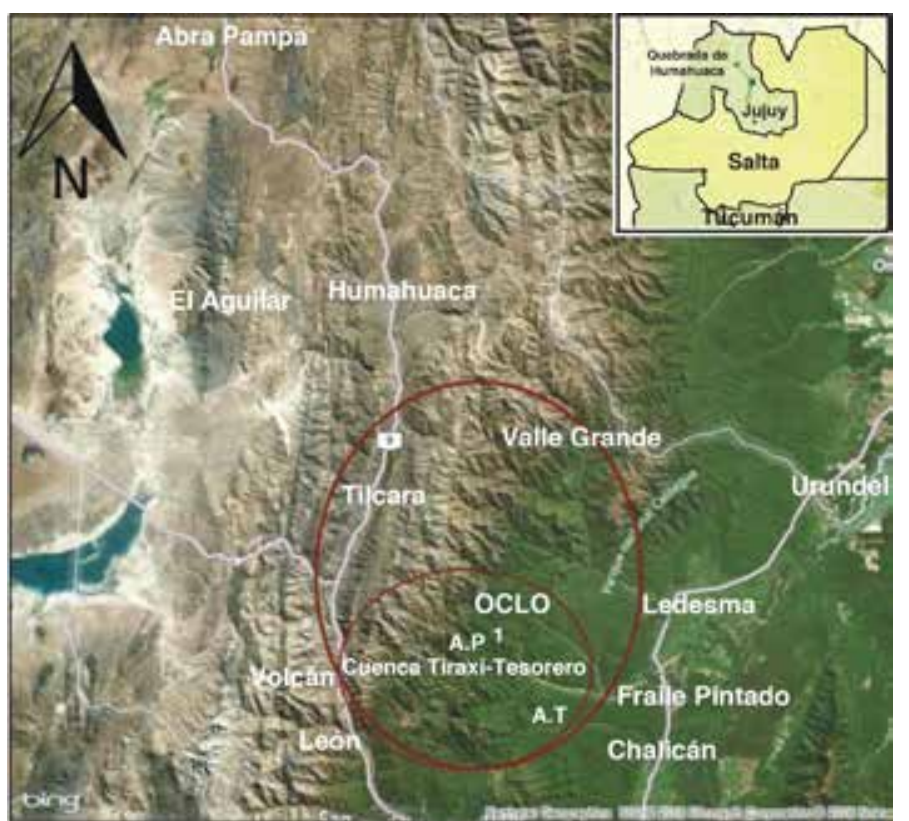


La muestra analizada está integrada por las pastas de cuarenta y una vasijas procedentes de los sitios Pucara de Tilcara, Angosto Chico, Pucara de Volcán, Esquina de Huajra y El Pobladito, ubicados en la quebrada de Humahuca $(\mathrm{N}=30)$ y de los sitios Álvarez Prado 1, Cucho de Ocloyas, Alto Calilegua, Antigal de Atacanas y Santa Bárbara en los valles orientales $(\mathrm{N}=11)$. La muestra reúne especímenes con diferente morfometría y patrones decorativos. Cada sección delgada fue realizada en uno de los fragmentos de cada vasija. En su mayoría integran la muestra vasijas fragmentadas procedentes de contextos de excavación y, en menor proporción, fragmentos de superficie (20\%), en ambos casos con decoración ACHI característica. En la Tabla 1 se indica la procedencia de cada una de las muestras analizadas.

Tabla 1. Procedencia de las muestras $\mathrm{ACH}$ analizadas

\begin{tabular}{|c|c|c|}
\hline Sitio & Referencia & Muestra \\
\hline \multicolumn{3}{|c|}{ Quebrada de Humahuaca } \\
\hline Pucara de Tilcara & Til1-38/1 111 & 1 \\
\hline Pucara de Tilcara & Til1-45/1621 & 2 \\
\hline Pucara de Tilcara & Til1-0/1577 St1 3c & 3 \\
\hline Pucara de Tilcara & Til1-0/601 St1 3B & 4 \\
\hline Pucara de Tilcara & Til1-0/1584 St1 3D & 5 \\
\hline Pucara de Tilcara & Til1-63.239.8M2 & 6 \\
\hline Pucara de Tilcara & Til1-0/R50 1727 & 7 \\
\hline Angosto Chico & Til9-0/721 & 8 \\
\hline Angosto Chico & Til9-394 (12) & 9 \\
\hline Angosto Chico & Til9-105 (M14) & 10 \\
\hline Pucara de Volcán & Tum1 B1 31.1-7 & 11 \\
\hline Pucara de Volcán & Tum1 B2 4.1-28 & 12 \\
\hline Pucara de Volcán & Tum1 B2 3.1-105 & 13 \\
\hline Pucara de Volcán & Tum1 R5 886 & 14 \\
\hline Pucara de Volcán & Tum1 R5 1062 & 15 \\
\hline Pucara de Volcán & Tum1 R5 C5N 5902 & 16 \\
\hline Pucara de Volcán & Tum1 R5 923 & 17 \\
\hline Esquina de Huajra & T1 C24-P-1593 & 18 \\
\hline Esquina de Huajra & T1 C24 s/no & 19 \\
\hline Esquina de Huajra & T3-988 TUMBA 4 & 20 \\
\hline Esquina de Huajra & T3-969 TUMBA 4 & 21 \\
\hline Esquina de Huajra & T3-962 & 22 \\
\hline Esquina de Huajra & T1LM9 17 & 23 \\
\hline Esquina de Huajra & T1LM9 18 & 24 \\
\hline Esquina de Huajra & T1LM9 C2P1507 & 25 \\
\hline El Pobladito (EP1) & TUM4-R2-P-1668 & 26 \\
\hline El Pobladito (EP3) & TUM4-R2-1481 & 27 \\
\hline El Pobladito (EP8) & TUM4-R2-1887 & 28 \\
\hline El Pobladito (EP2) & TUM4R2 1583 & 29 \\
\hline El Pobladito & TUM4R3 2278 & 30 \\
\hline \multicolumn{3}{|c|}{ Valles Orientales (yungas) } \\
\hline Álvarez Prado 1 & AP1 R2 64.1.1 & 31 \\
\hline Cucho de Ocloya & OCLO M20 & 32 \\
\hline Cucho de Ocloya & OCLO M1 & 33 \\
\hline Cucho de Ocloya & OCLO M11 & 34 \\
\hline Alto Calilegua & AC5 & 35 \\
\hline Alto Calilegua & AC6 & 36 \\
\hline Alto Calilegua & $\mathrm{AC7}$ & 37 \\
\hline Antigal de Tacanas & AT 3 R5S2-15 & 38 \\
\hline Antigal de Tacanas & AT 4 R1S1-15 & 39 \\
\hline Antigal de Tacanas & AT 5 R5S1-13 & 40 \\
\hline Sta Bárbara & SB1 & 41 \\
\hline
\end{tabular}


La caracterización petrográfica de las pastas cerámicas se realizó en un microscopio Leica DM $750 \mathrm{P}$ con accesorio fotográfico siguiendo los procedimientos usuales en petrografía cerámica (Freestone, 1991; Stoltman, 1999; Quinn, 2013, entre otros). Las fases plásticas como los elementos no plásticos menores a $15 \mu \mathrm{m}$ fueron considerados como parte de la matriz arcillosa teniendo en cuenta coloración y estructura según la clasificación de Curtois (1976). En la identificación mineralógica de las inclusiones mayores a $15 \mu \mathrm{m}$ se distinguió entre cristaloclastos y litoclastos. Se registraron las medidas, formas y proporciones de los diferentes tipos de inclusiones no plásticas y cavidades; esto último mediante point counting. Paralelamente se tomaron fotomicrografías de sectores de las pastas.

Para el análisis mediante point counting se aplicó el método de intercepción múltiple (multiple interception) con una medición promedio de 300 puntos por sección delgada. Esta cantidad de puntos aportó la información necesaria para encarar posteriores comparaciones estadísticas dirigidas a una clasificación de las pastas mediante la identificación de diferentes agrupamientos. En la Tabla 2 pueden observarse los porcentajes de los componentes identificados en cada pasta analizada: cuarzo, plagioclasas, biotita, muscovita, feldespato potásico, hornblenda, óxido de hierro, filitas/pizarras, arenisca, cuarcita, calcita, arcillita/limolita, granito, tiesto molido, vulcanitas (basalto) y anfíbol/piroxeno). A los mencionados se agregan los porcentajes de matriz arcillosa y de cavidades no incluidos en la Tabla 2 por razones de espacio.

Los grupos de pastas fueron definidos combinando los atributos cualitativos observados en microscopio con la técnica de Análisis de Conglomerados (cluster analysis), aplicando el programa PAST versión 3.14 (Hammer et al. 2001) a los datos cuantitativos obtenidos mediante point counting. 
产

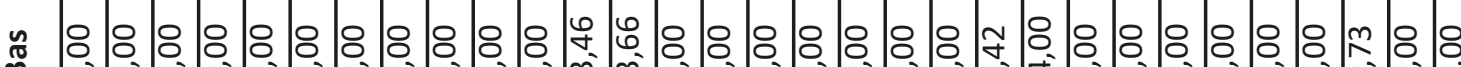

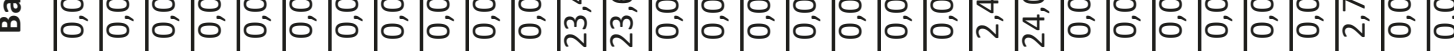

12 -

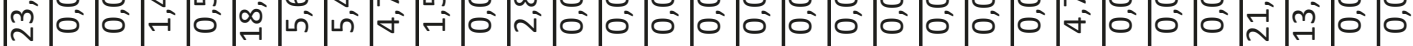

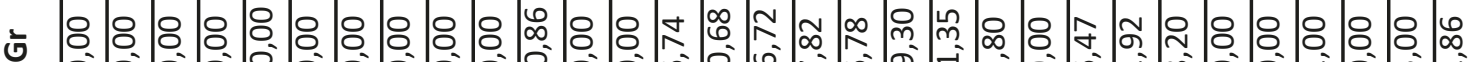

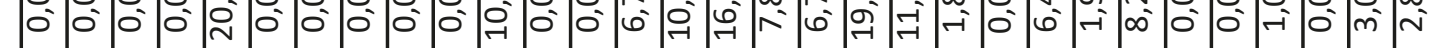

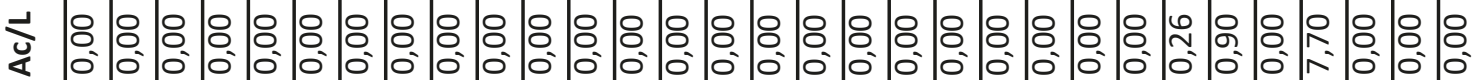

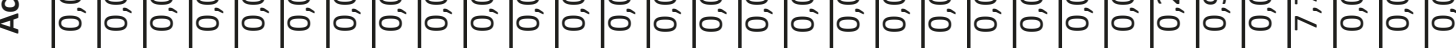

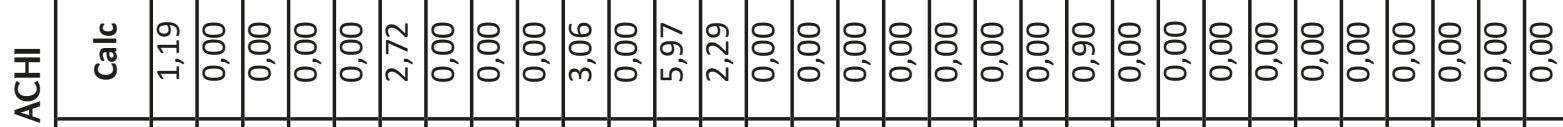

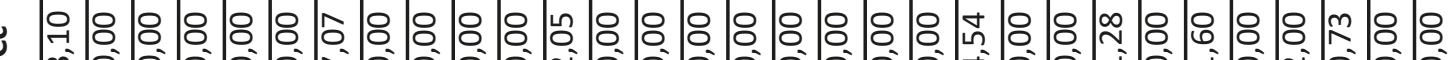

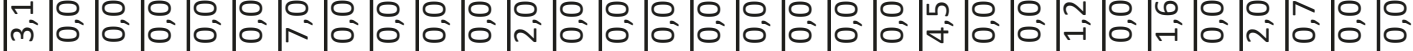

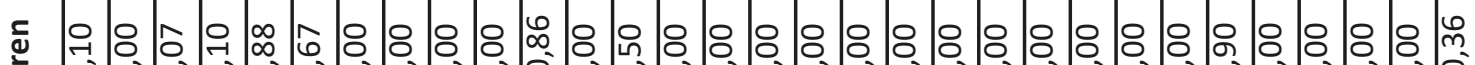

n o

。

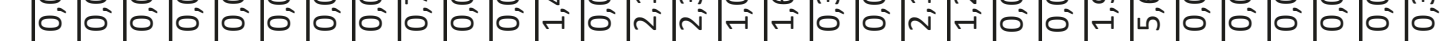

을

๕ั 흔

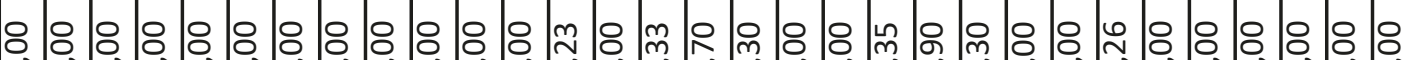

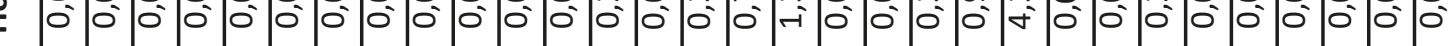

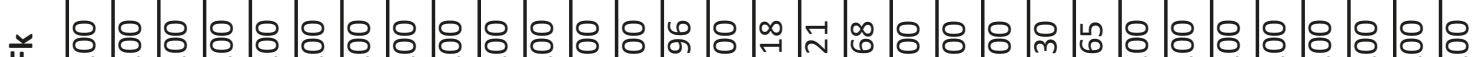

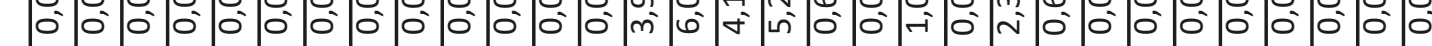

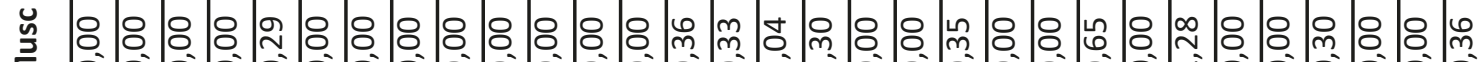

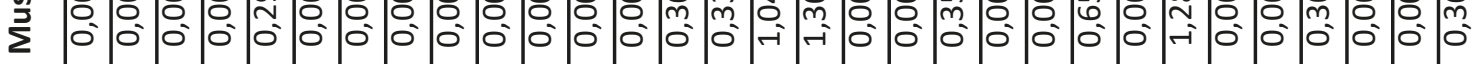

.0 \& \&

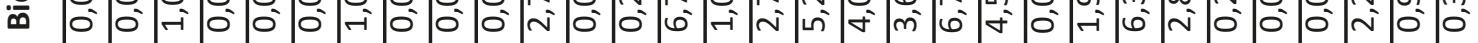

$\infty$ m

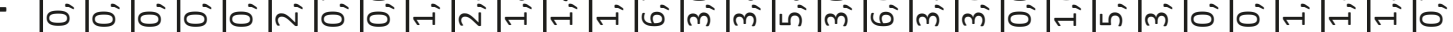

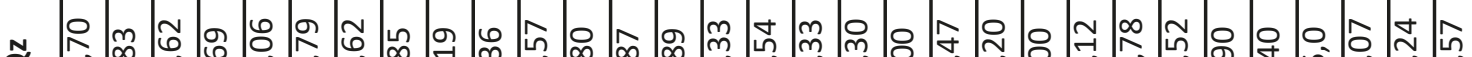

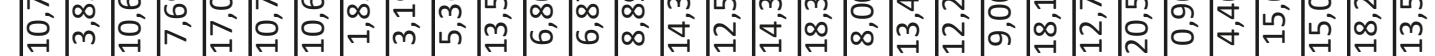




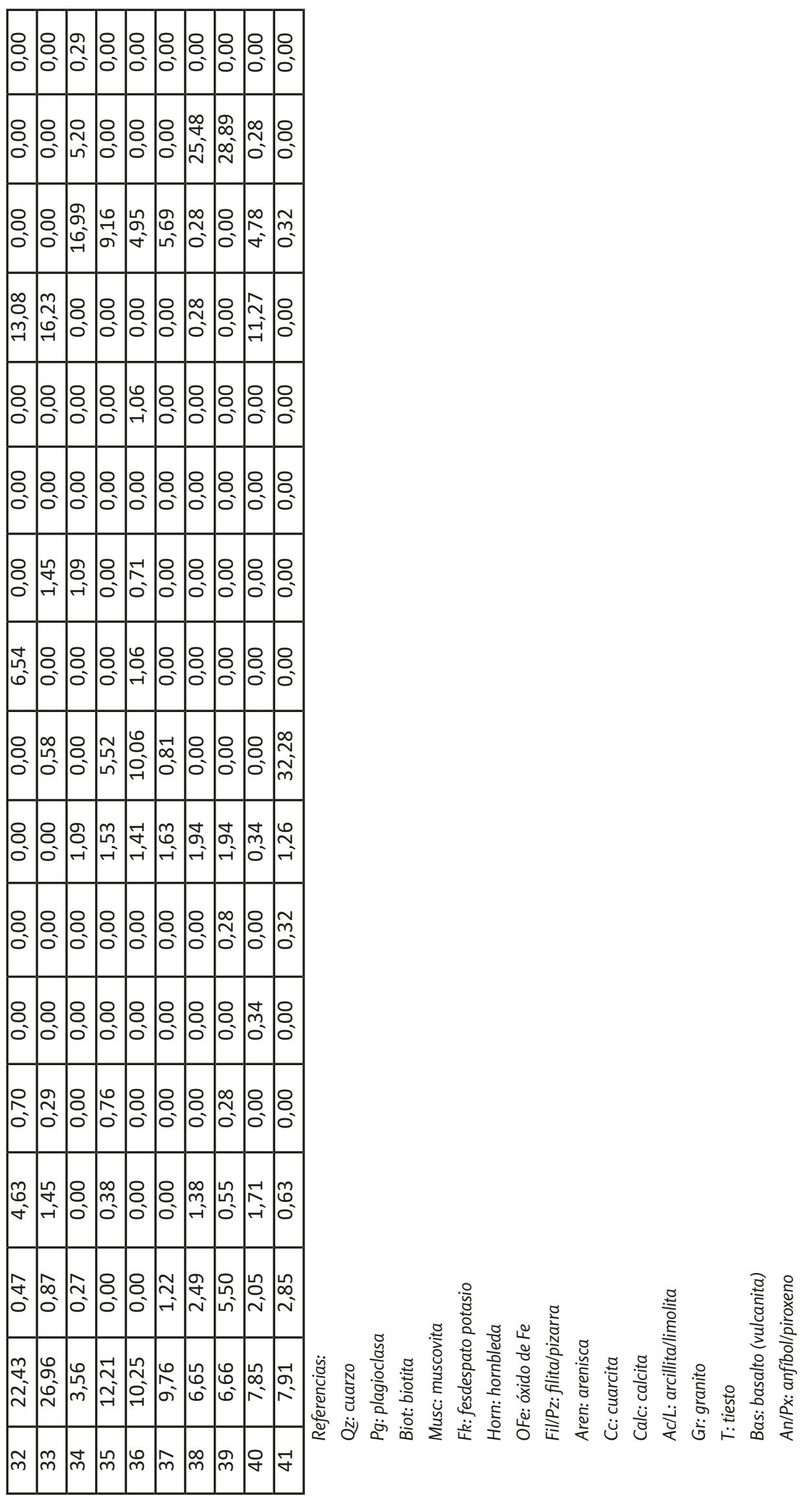




\section{Variaciones en el modo de hacer las pastas}

El análisis petrográfico de cuarenta y una pastas de vasijas ACHI, halladas en sitios de la quebrada de Humahuaca y de los Valles Orientales (yungas), permitió identificar seis tipos de pastas ordenados en cuatro grupos composicionales básicos. El procedimiento analítico llevado a cabo incluyó la caracterización de las inclusiones no plásticas, cavidades y matriz arcillosa en cada sección delgada; la distribución modal de todos los componentes mediante point counting y el procesamiento estadístico multivariado de los datos cuantitativos (cluster analysis) aplicando el Programa Past versión 3.14.

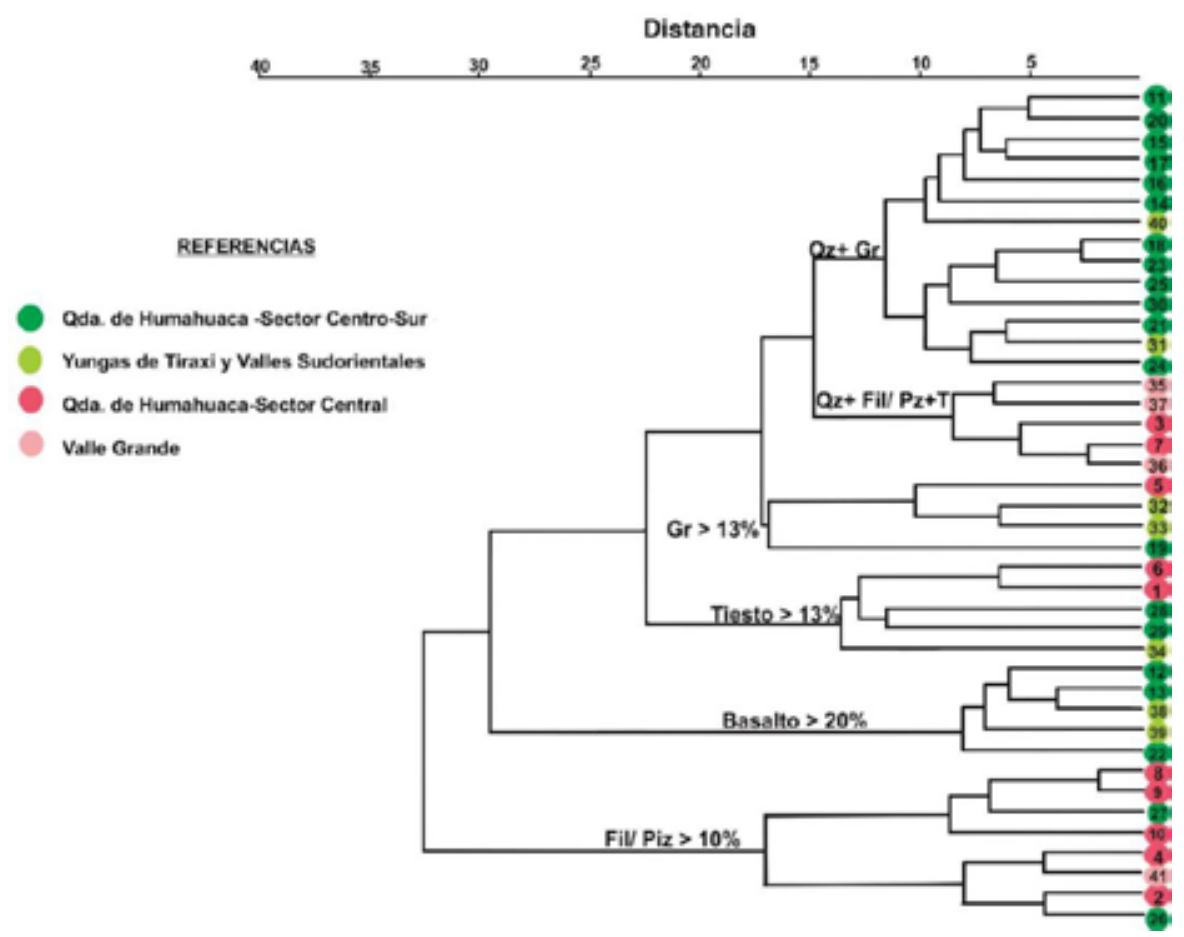

Grupo 1 con su variante 1.1: $N=18(44 \%)$

Muestras: 11-20-15-17-16-14-40-18-23-25-30-21-31-24-5-32-33-19.

Pastas con inclusiones no plásticas mayoritarias de cuarzo (7,85\% a $26,96 \%)$ y granito $(1,80 \%$ a $20 \%)$. La variedad 1.1 agrupa a cuatro pastas (5 a 19) con elevado porcentaje de granito $(\geq 13 \%)$. La muestra 5 del Pucara de Tilcara es la única pasta del sector central de la quebrada de Humahuaca que corresponde a este grupo, las 17 restantes provienen de sitios del Departamento Tumbaya: Pucara de Volcán (Tum1), Esquina de Huajra (Tum10) y El Pobladito (Tum4) y de sitios ubicados en los valles surorientales (Antigal de Tacanas, AP1 y Cucho de Ocloyas).

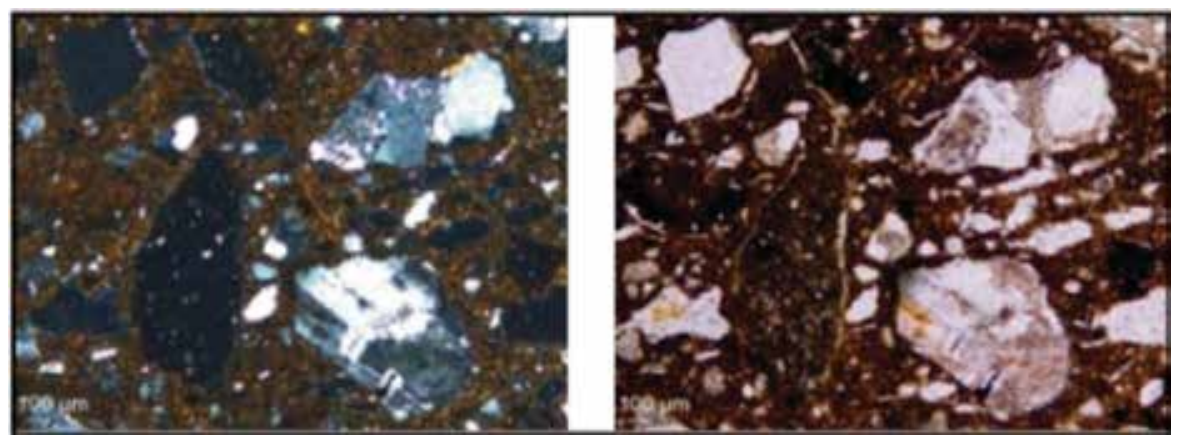

Figura 3. Fenograma con la representación de los agrupamientos de pastas $\mathrm{ACH}$ tomando como variables los datos cuantitativos registrados mediante point counting. Programa Past 3.14, método Ward. Coeficiente de Correlación Cofenética. CCC: 08298.
Figura 4. Muestra 40. AT5 R5E1-13. Granito 11,27\%, cuarzo 7,85. Izquierda: nicoles cruzados. Derecha: nicoles paralelos. 
Figura 5. Muestra 16. $\mathrm{TUM}_{1} \mathrm{R}_{5} \mathrm{C}_{5} \mathrm{~N}$ 5902. Granito $16,72 \%$, cuarzo $12,54 \%$. Izquierda: nicoles cruzados. Derecha: nicoles paralelos.

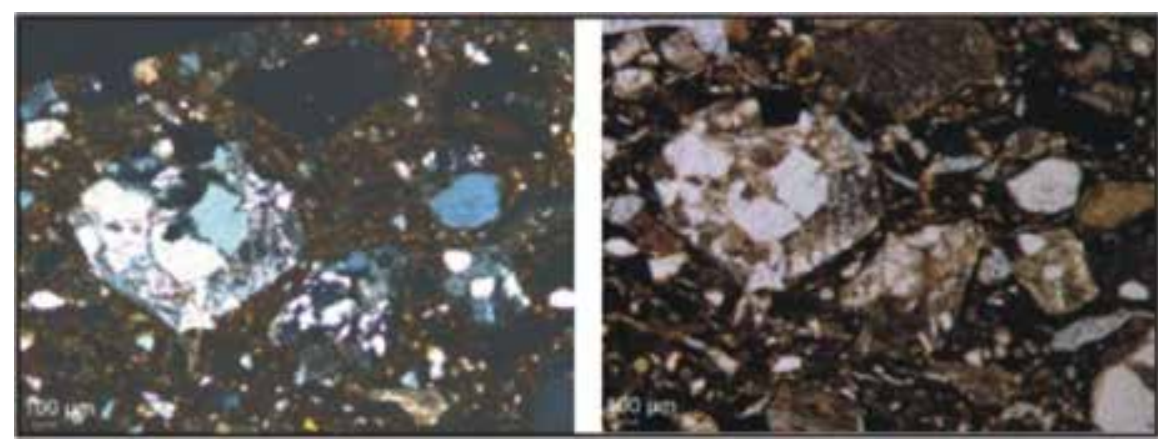

Grupo 2 con sus variantes 2.1, 2.2 y 2.3: $N=13$ (32\%)

Muestras: 35-37-3-7-36-8-9-27-10-4-41-2-26.

Pastas con litoclastos de pizarras y filitas, cuarzo y eventual presencia de tiesto molido en porcentajes que no superan el 6\%. La variante 2.1 reúne pastas con los porcentajes más bajos $(0,81 \%$ a $9,54 \%)$ de pizarras y filitas $(\leq 10 \%)$. La variante 2.2 presenta abundantes litoclastos (15,32\% a $41 \%)$. La variante 2.3 se caracteriza por filitas angulosas marrones en general de granulometría gruesa a muy gruesa. Las vasijas de este grupo provienen de los sitios Pucara de Tilcara (Til1) y Angosto Chico (Til9) del sector central de la Quebrada y de los valles orientales próximos (sitios Alto Calilegua y Santa Bárbara, ambos en Valle Grande). En este grupo solo queda incluida una pasta de El Pobladito.

Figura 6. Izquierda: nicoles cruzados: a) superior: muestra 3. St 13 Til 1-1577.

Pz/Fil: 9,54\%, arenisca 7,07\%, cuarzo 10,62\%; b) inferior: muestra 26. Tum4 $\mathrm{R}_{2} \mathrm{P} 1668 \mathrm{Pz} / \mathrm{Fil}$ 41\%, cuarcita 1,60\%, cuarzo 0,90\%. Derecha: nicoles paralelos.

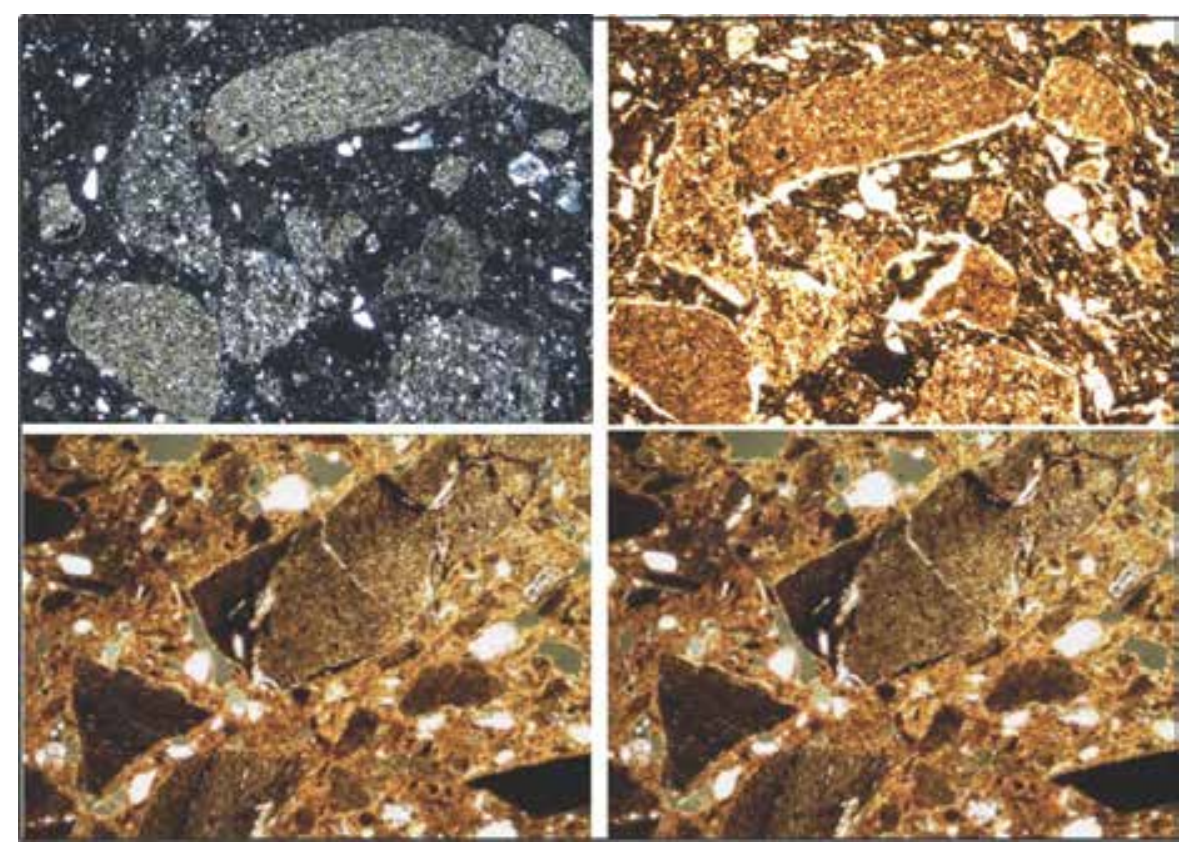




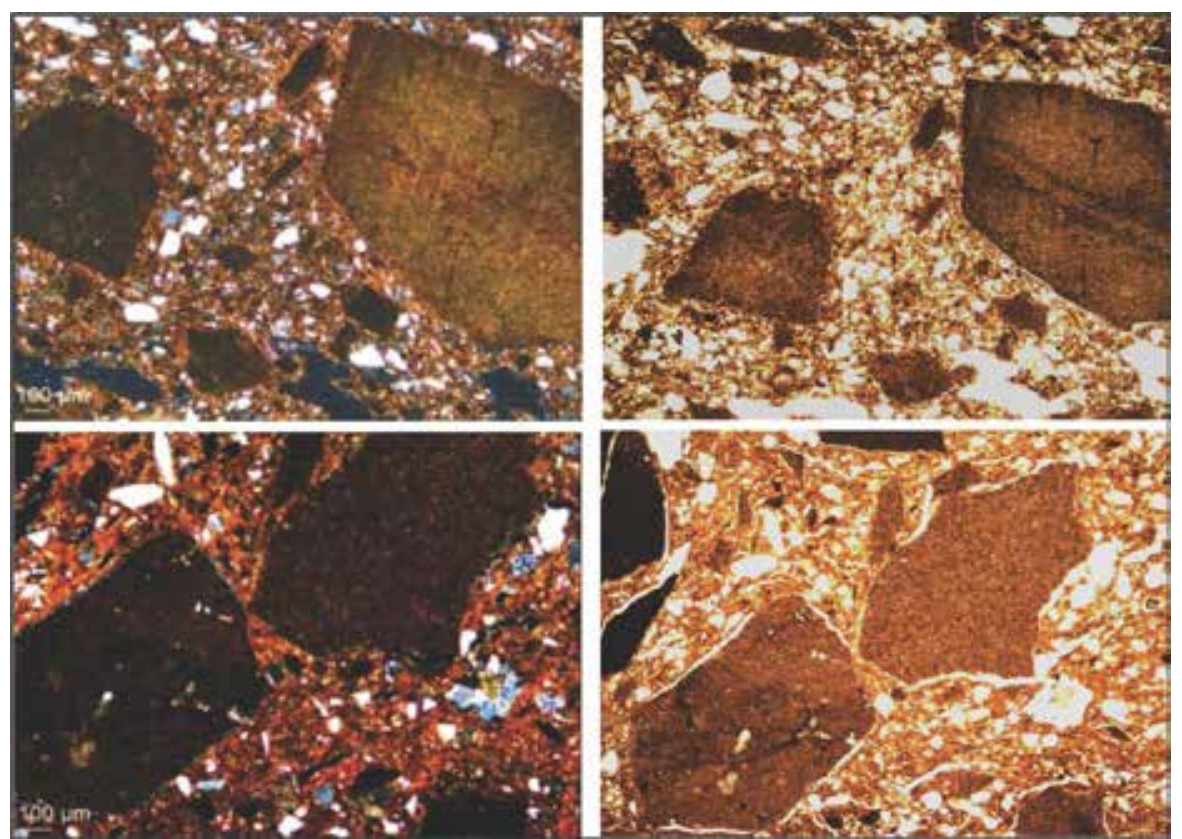

Grupo 3: $N=5(12 \%)$

Muestras: 6-1-28-29-34.

Pastas con un porcentaje superior al $10 \%$ de tiesto molido, indicando el agregado intencional de este material como antiplástico. Presentan además cuarzo (3,56\% a $15 \%)$, cuarcita o arenisca en bajas proporciones $(\leq 3 \%)$ y, eventualmente pizarras y filitas (hasta 10\%) o muy escaso granito. Las muestras corresponden a dos vasijas del Pucara de Tilcara, dos del sitio El Pobladito y una del Cucho de Ocloyas.
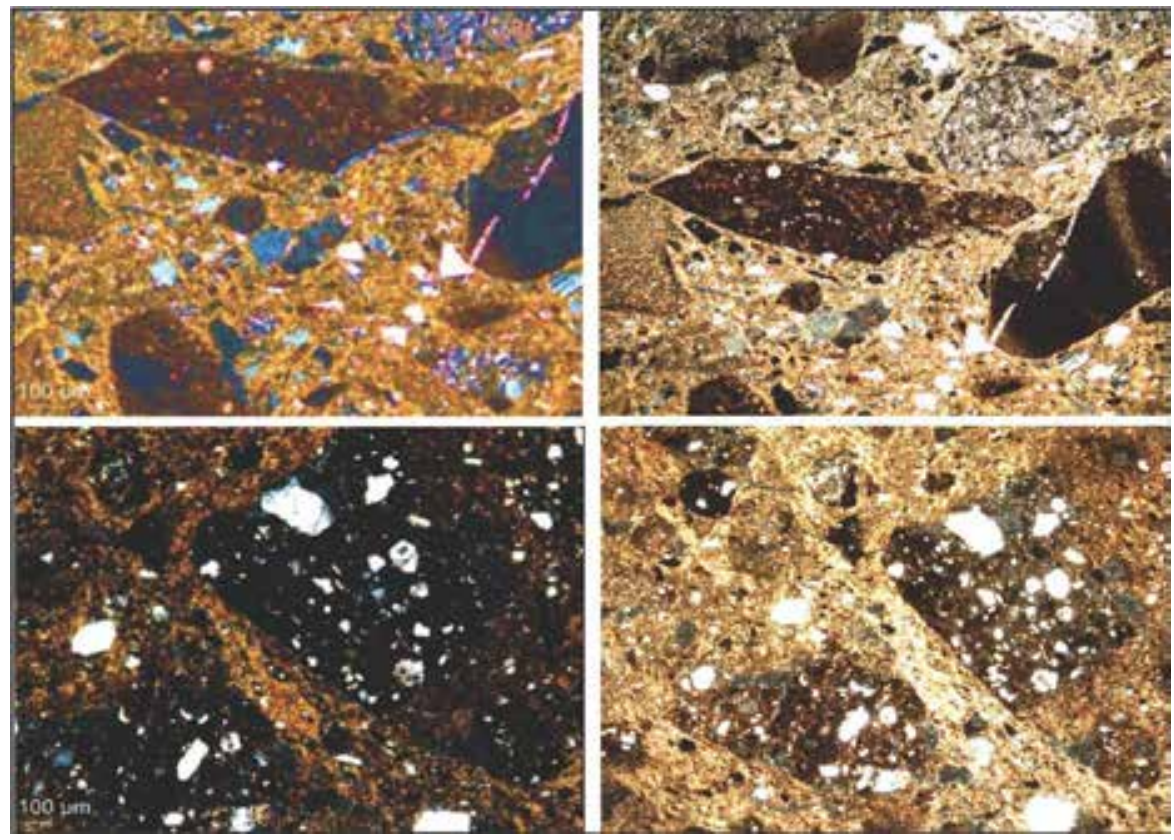

Figura 7. Pastas $\mathrm{ACHI}$ con filitas marrones. Izquierda: nicoles cruzados: a) superior: muestra 41. Santa Bárbara Sb1 (filitas 32,29\%); b) inferior: muestra 10 Tilg105 (filita 15,31\%). Derecha nicoles paralelos.
Figura 8. Izquierda: nicoles cruzados: a) superior: muestra 6. Til 163.238 con $18,87 \%$ de tiesto y $10 \%$ de pizarras/filitas y cuarzo, b) inferior: muestra 34. OCLO M11 con $17 \%$ de tiesto, 20\% de cuarzo 5,20\% de basalto y $1 \%$ de cuarcita. Derecha: nicoles paralelos. 
Figura 9. Muestra 38 Antigal de Tacanas 3: 25,48\% de basalto, $10 \%$ cuarzo. Izquierda: nicoles

Figura 10. Muestra 22. Tum10 T3 962: 24\% de basalto y $9 \%$ de cuarzo. Izquierda: nicoles cruzados. Derecha: nicoles paralelos.

Figura 11. Ejemplos de covariación frecuente entre grupos petrográficos de pastas, tipos de incisiones y características morfológicas. A: Grupo 1 con granito-cuarzo y Grupo 4 con basalto. B: Grupo 2 con abundante filita y pizarra. C: Grupo 3 con abundante tiesto molido.

\section{Grupo 4: $N=5(12 \%)$}

Muestras: 12-13-38-39-22.

Pastas con un porcentaje superior al 20\% de vulcanitas (litoclastos redondeados y subredondeados de basalto). Otros componentes: calcita (2,29\% a 6\%), OFe, hornblenda, biotita y plagioclasas en bajas proporciones y $6 \%$ a $8 \%$ de cuarzo. Corresponden a vasijas del sector centro-sur de la Quebrada (Pucara de Volcán y Esquina de Huajra) y de los valles sudorientales (sitio Antigal de Tacanas), mostrando una situación similar a la del Grupo 1.
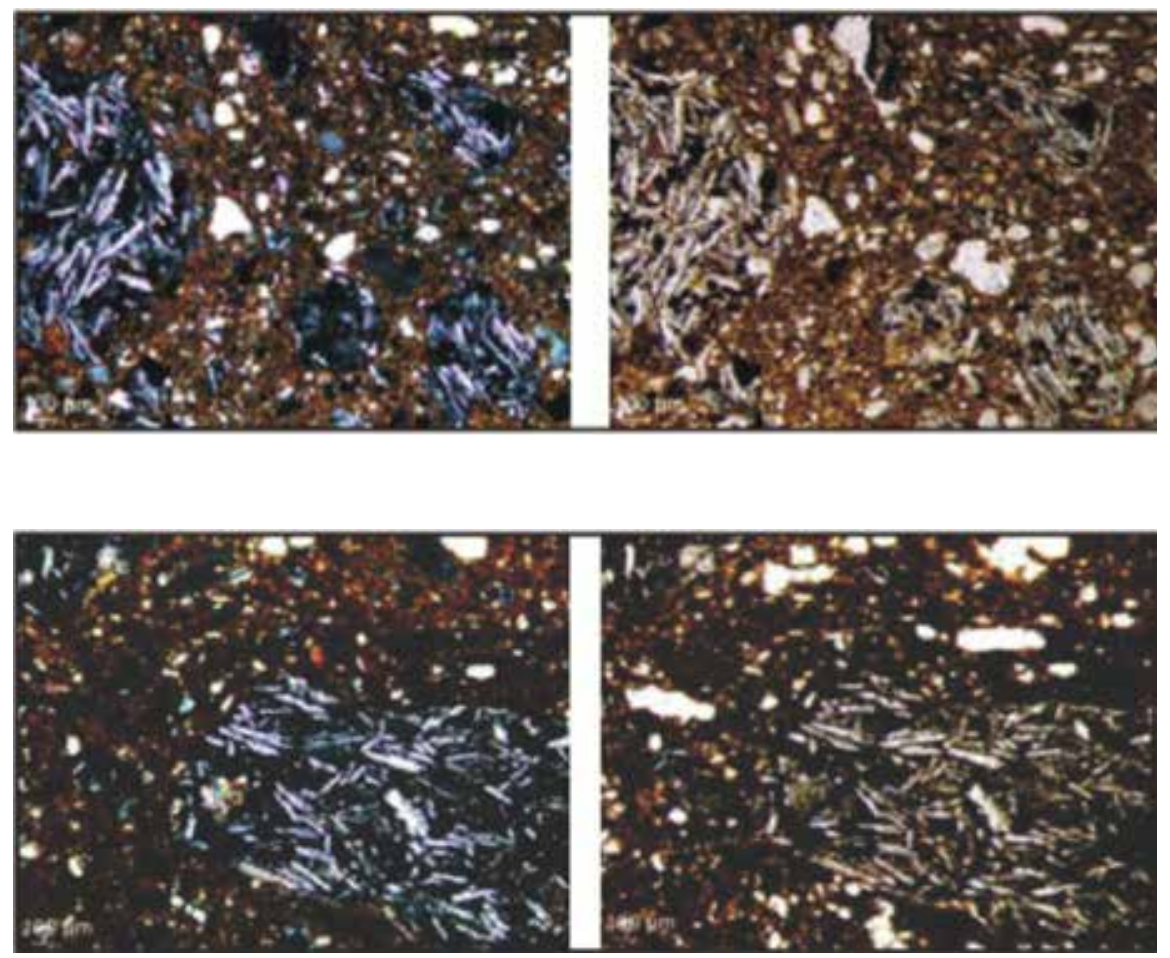

Las pastas de todos los grupos presentan matrices arcillosas de estructura predominantemente seudolepidoblástica (con abundantes micas detríticas). La coloración de las mismas indica cocciones oxidantes completas e incompletas, siendo muy comunes los fondos marrones y grisáceos. En general son pastas poco compactas con $10 \%$ en promedio de espacio ocupado por cavidades, e inclusiones no plásticas de granulometría media a gruesa abundantes (>30\%).
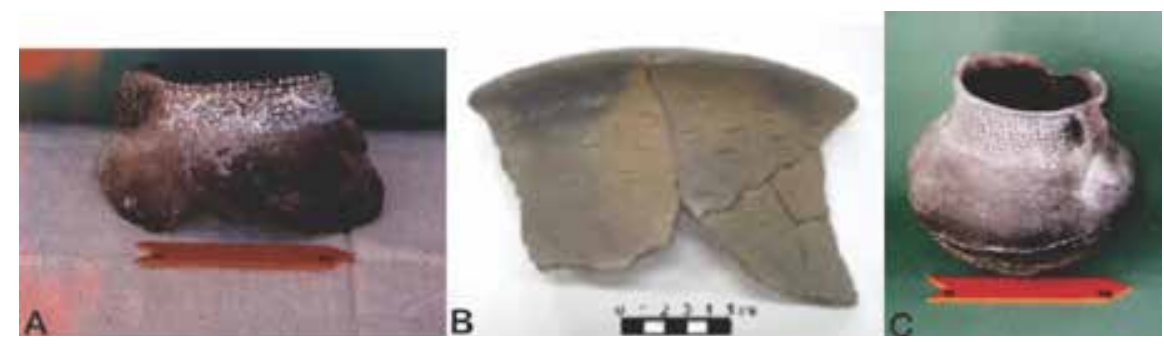
La vinculación entre grupos de pastas, morfología de las vasijas y tipo de decoración en los casos discernibles ha permitido registrar que:

a) Las vasijas con pastas del Grupo 1 (con abundante granito y cuarzo) presentan una gama amplia de variantes decorativas en sus cuellos. Sin embargo, son predominantes las incisiones ovales, subtriangulares y triangulares, respecto de las grandes arrastradas horizontales. Predominan las ollas pequeñas y medianas con asas retorcidas y aditamentos modelados en la base de las asas.

b) En las vasijas con pastas del Grupo 2, con porcentajes muy elevados de litoclastos de filitas y pizarras de la Formación Puncoviscana, predominan las hileras de incisiones grandes arrastradas o subtriangulares. En Tilcara como en Tumbaya corresponden a ollas y cántaros en general grandes de mayor popularidad durante el incaico.

c) En las vasijas del Grupo 3 con agregado de tiesto molido predominan las incisiones pequeñas ovales. Se registró una olla de la variante 6 para el Pobladito y otro ejemplo es la olla con incisiones punteadas desordenadas delimitadas por línea incisa en zigzag en la inserción cuello-cuerpo del Pucara de Tilcara.

d) En las pastas del Grupo 4 que presentan un porcentaje elevado de litoclastos de basalto, la situación es análoga a la del Grupo 2 con predominancia de incisiones subovales, subtriangulares y circulares correspondientes a vasijas medianas (ollas y cántaros).

\section{Resultados}

Hemos registrado una correlación directa entre las pastas de cada sector de la quebrada de Humahuaca con los valles orientales más próximos a ellos. Es decir, de Valle Grande con los sitios Pucara de Tilcara y Angosto Chico, y de las yungas de la cuenca de los ríos Tiraxi-Tesorero y valles ubicados al noreste del valle de Jujuy con los sitios Pucara de Volcán, Esquina de Huajra y El Pobladito. Esta evidencia reflejaría que los contactos oeste-este en la misma latitud fueron más intensos que los contactos norte-sur.

Por otro lado, si bien el fenograma obtenido (Figura 3) facilitó la visualización de los grupos descriptos y es coherente con lo observado en el microscopio, otras evidencias derivadas de las caracterizaciones petrográficas resultan ser significativas a la hora de interpretar los modos de hacer del estilo ACHI. Si prestamos atención a la presencia de ciertos cristaloclastos y litoclastos en porcentajes muy bajos, vemos que, por ejemplo, casi el $50 \%$ de las pastas analizadas contiene granito y que el $25 \%$ contiene basalto. Tanto el granito como el basalto no aparecen en las pastas de producción local de los sectores considerados de la quebrada de Humahuaca, perteneciendo ambos a ambientes geológicos más orientales. Congruentemente, como se ilustra en la Figura 11, las arenas del río Grande de la quebrada de Humahuaca y de sus afluentes no presentan granito o basalto. 
Figura 12. Arriba: arena del río Huasamayo (Departamento Tilcara). Abajo: arena del río Grande a la altura de Volcán (Departamento Tumbaya). Izquierda: nicoles cruzados. Derecha: nicoles paralelos. Sin litoclastos graníticos ni vulcanitas (basalto).

Figura 13. Arena con basalto de un afluente del río Ocloyas (cuenca de los ríos Tiraxi-Tesorero). Izquierda: nicoles cruzados. Derecha: nicoles paralelos.

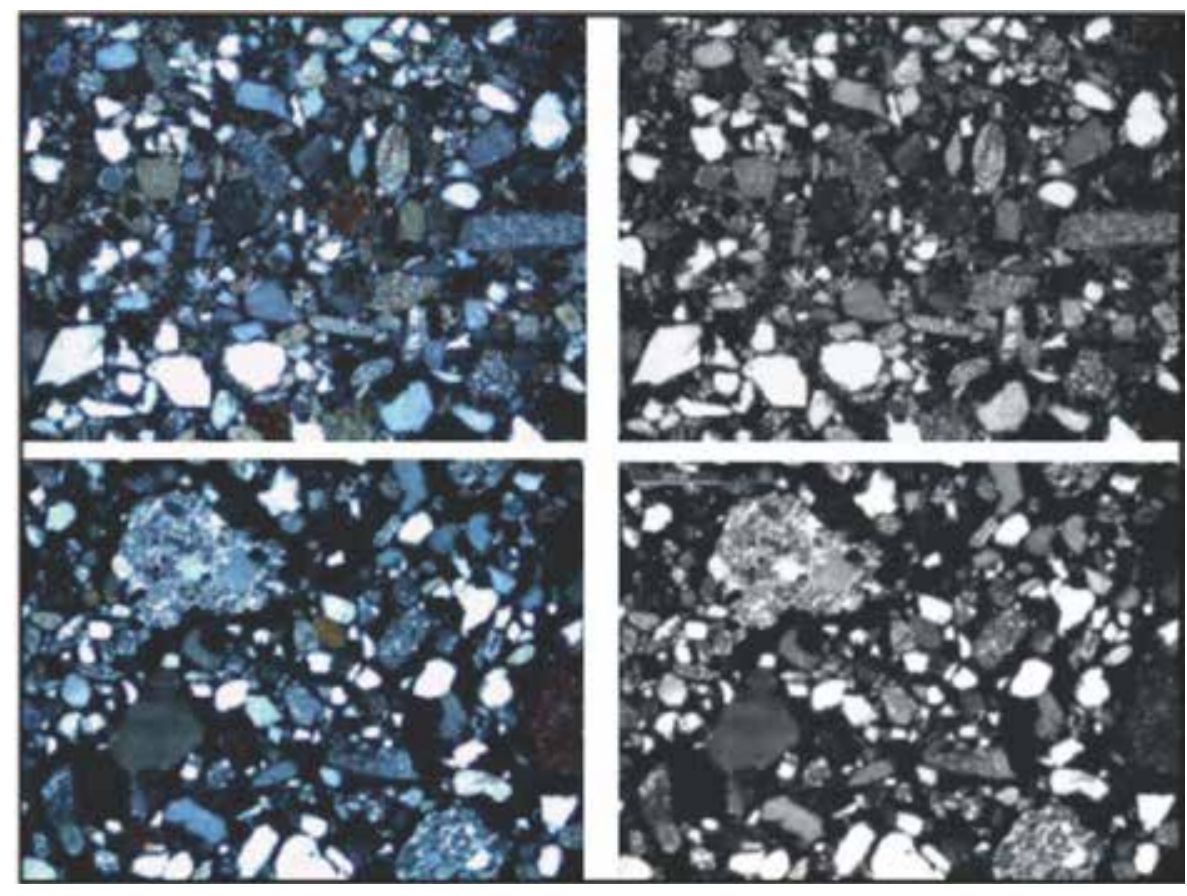

Por el contrario, basaltos idénticos a los de las pastas fueron detectados en las arenas de un afluente del río Ocloyas ubicado al pie del sitio Cucho de Ocloyas (Figura 12). Estas inclusiones aparecen también ampliamente distribuidas en las pastas de manufactura local del sitio Antigal de Tacanas (Garay de Fumagalli, 2003). Las inclusiones de basalto permiten delimitar áreas de procedencia de las vasijas que los contienen ya que, curiosamente hasta el momento, ninguna vasija ACHI de Tilcara y Valle Grande las presentan.

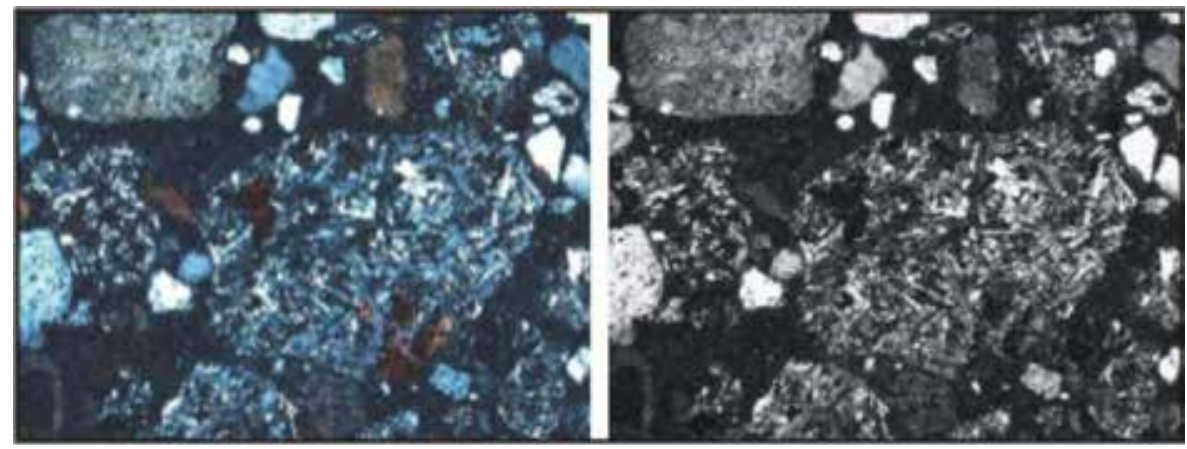

Del total de las pastas estudiadas, quince presentan litoclastos de pizarras y/o filitas típicas de la Formación Puncoviscana, sin acompañamiento de granito ni basalto, pudiendo ser por ello de manufactura local en la quebrada de Humahuaca. Dentro de este grupo existen algunas variaciones granulométricas y texturales. En este sentido, llama la atención la presencia de inclusiones grandes y angulosas de filitas marrones (Figura 7) en las pastas 4, 10, 35, 36 y 41. La recurrencia de estas inclusiones en las pasta de Santa Bárbara (observadas con lupa binocular y en secciones delgadas), indica que, posiblemente, las vasijas 4 y 10 (Pucara de Tilcara y Angosto Chico Inciso, respectivamente) fueran manufacturadas en la región oriental de Valle Grande.

Análisis composicionales realizados previamente mediante aplicación de Fluorescencia de Rayos X (FRX) relacionaron estrechamente una pasta ACHI (18) del Pucara de Volcán con la arcilla 40, procedente de los sedimentos lacustres ubicados frente al pucara (Cremonte y Solís, 1999). Este tipo de sedimento arcilloso también habría sido utilizado en la manufactura de otras vasijas integrantes de la muestra analizada: 
Marrón Ordinario; Marrón Alisado, un aríbalo castaño; escudillas Humahuaca Negro sobre Rojo y Humahuaca Inca. Todas ellas presentaron concentraciones análogas de los elementos traza $\mathrm{Cr}, \mathrm{Co}, \mathrm{Zn}, \mathrm{Rb}, \mathrm{V}$, Sr y de los elementos mayoritarios $\mathrm{O} 2 \mathrm{Si}$, OMg, OMn, OP, O3Fe2 (Cremonte et al., 1999: 21). La pasta ACHI 18 del Pucara de Volcán corresponde a la $13 \mathrm{AB}$ de la clasificación en lupa binocular e integra el Grupo petrográfico 2, caracterizado por abundantes inclusiones de pizarras/filitas de la Formación Puncoviscana, como es lo corriente en la tradición de manufactura de la quebrada de Humahuaca. Este análisis refuerza la hipótesis de la manufactura local de las vasijas $\mathrm{ACHI} 13 \mathrm{AB}$ con litoclastos de la Formación Puncoviscana sin las filitas marrones.

En relación con las cinco vasijas con agregado intencional de tiesto molido, podemos decir que no se trata de un comportamiento de manufactura propio de la tradición alfarera de la quebrada de Humahuaca. En la provincia de Jujuy, el tiesto molido ha sido profusamente identificado en las alfarerías de la Tradición San Francisco del período Formativo (Dougherty, 1975, Cremonte et al., 2016; Pereyra Domingorena y Cremonte, 2017), que tiene su área nuclear en la cuenca del río San Francisco, precisamente en las Yungas orientales.

Por último, no podemos obviar el comportamiento particular de las pastas del sitio preinca El Pobladito de Tumbaya. Las cinco pastas analizadas se distribuyen en cuatro grupos diferentes. Si bien la muestra analizada es pequeña y no se han podido hacer comparaciones con fragmentos ACHI contemporáneos de otros sitios del Departamento Tilcara ni de los valles orientales, quizás las diferencias observadas estén reflejando un momento inicial en la conformación de este estilo con mayor variabilidad en los modos de hacer.

\section{Discusión y comentarios finales}

En su trabajo de 1994, Ottonello planteó la posibilidad de que el estilo Angosto Chico Inciso tuviera su origen en el componente San Francisco Ordinario, que habría perdurado como manifestación empobrecida del Complejo San Francisco (SF) según el modelo planteado por Dougherty (1975). Si este fuera el caso, grupos étnicos orientales se habrían desplazado hacia la quebrada de Humahuaca, teniendo mayor incidencia en el sector centro-sur considerando su elevada representatividad (op. cit.: 342). Desde la perspectiva del aporte de las tradiciones de manufactura evidenciadas en la combinación de las elecciones tecnológicas, hemos comparado las pastas cerámicas San Francisco con las Angosto Chico Inciso como implicancias de contrastación que permitan —aunque sea en parte- poner a prueba la hipótesis de Ottonello.

La ocupación efectiva San Francisco en el sector centro-sur de la quebrada de Humahuaca $(2.000 \mathrm{msnm})$, por debajo de la instalación tardía del Pucara de Volcán (Cremonte y Garay de Fumagalli, 2001) ha sido planteada en otras oportunidades. Dicha ocupación, fechada a principios de la Era Cristiana (Beta-119669: $1940 \pm 40$ AP, 1 sigma: 45-110 d. C. y 2 sigma: 5 a. C. - 145 d. C.; Beta 119670: $1940 \pm 70$ AP, 1 sigma 5-135 d. C. y 2 sigma: 60 a. C. - 240 d. C.), pudo tener como objetivo una ampliación en la explotación de sus recursos económicos. Asimismo, pudo favorecer interacciones a corta y larga distancia con otras sociedades de la quebrada de Humahuaca y de la Puna, de las cabeceras de la quebrada del Toro (Provincia de Salta) y con los oasis de San Pedro de Atacama.

Recientemente, el hallazgo en superficie de fragmentos San Francisco en el área agrícola de Raya-Raya en la quebrada de Tumbaya Grande (Scaro, 2015) puede ser interpretado como parte del mismo proceso de ocupación territorial. Debido a que no existen diferencias en las pastas, tratamientos y acabados de superficie, entre los conjuntos hallados en Raya Raya y por debajo de las ocupaciones del Pucara de Volcán con las 
del río San Francisco estudiados por Dougherty (1975) y Ortiz (2003) es que pensamos en una ampliación del territorio de las sociedades San Francisco hacia un ambiente más elevado pero de contacto entre la Prepuna y las yungas, ya en los inicios de la Era Cristiana (Pereyra Domingorena y Cremonte, 2017).

El análisis petrográfico comparativo entre cuarenta y cuatro muestras cerámicas SF procedentes de los sitios de Volcán y Raya Raya de la quebrada de Humahuaca y de los sitios Pozo de la Chola y Finca Santa María del sector medio-superior de la cuenca del río San Francisco (Pereyra Domingorena y Cremonte, 2017) permitió identificar 4 grupos generales de pastas (Tabla 3 ).

Tabla 3. Distribución modal en \% (point counting) de inclusiones no plásticas, matriz y cavidades de los Grupos de pastas San Francisco (adaptado de Pereyra

Domingorena y Cremonte, 2017)

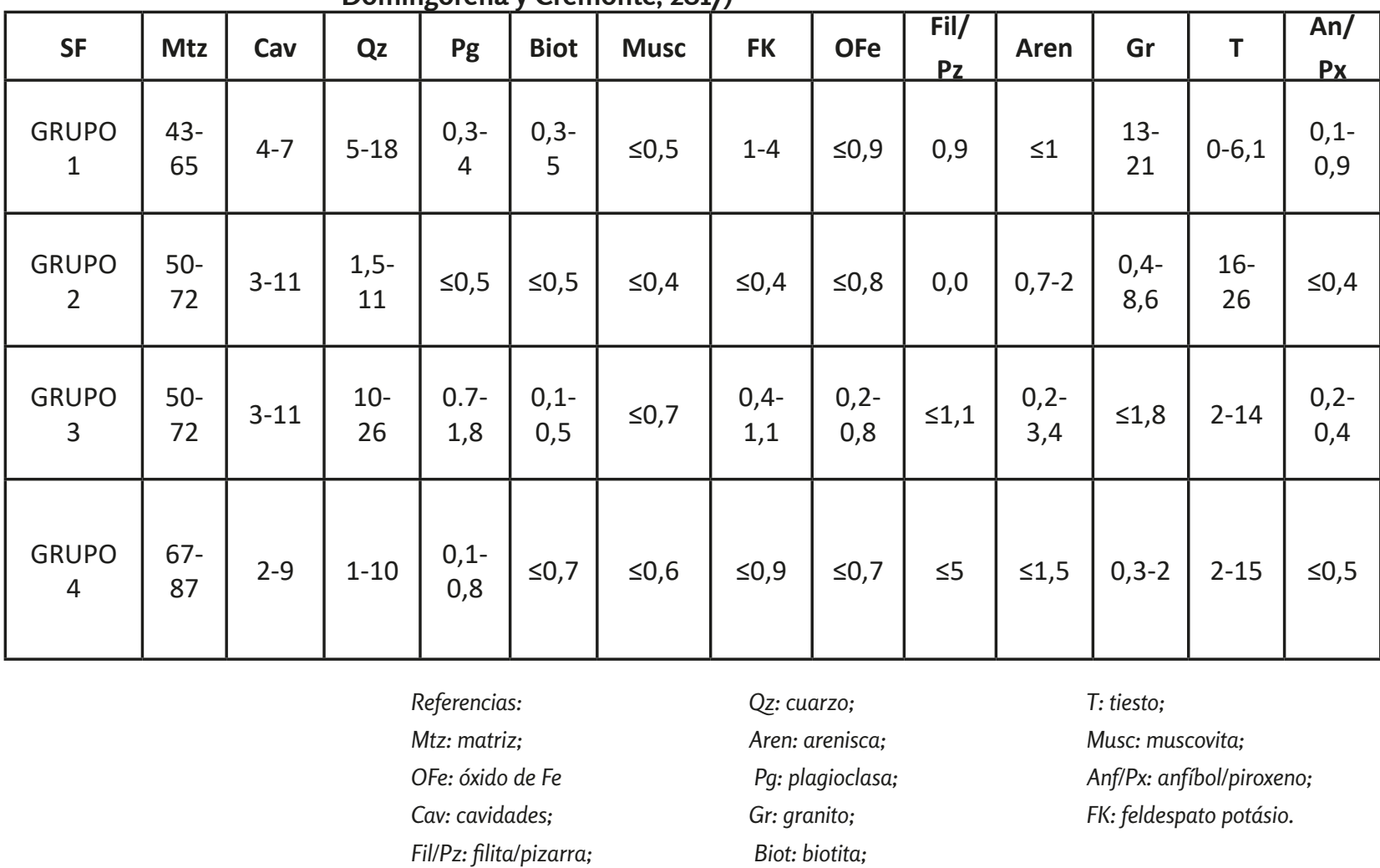

La gran mayoría de las pastas SF contiene tiesto molido y cuarzo. Sin duda, las pastas SF y ACHI de fondo seudolepidoblástico y abundantes inclusiones grandes de granito y cuarzo son similares. Sin embargo, ello no permite plantear una derivación directa de las primeras respecto de las segundas debido a que, por ejemplo, hemos registrado pastas similares en otros contextos alfareros como ocurre con las cerámicas muy tempranas del sitio Cueva de Cristóbal (Cremonte y Botto, 2016) no asignables al San Francisco. Dichas similitudes deben ser referidas a la selección de materias primas accesibles localmente, adecuadas como antiplásticos para vasijas de uso culinario. Como es sabido, el agregado de una arena cuarzosa gruesa puede favorecer la conductividad calórica, convirtiendo al material apto para la manufactura de ollas para cocinar (Arnold, 1985; Rye, 1981). 

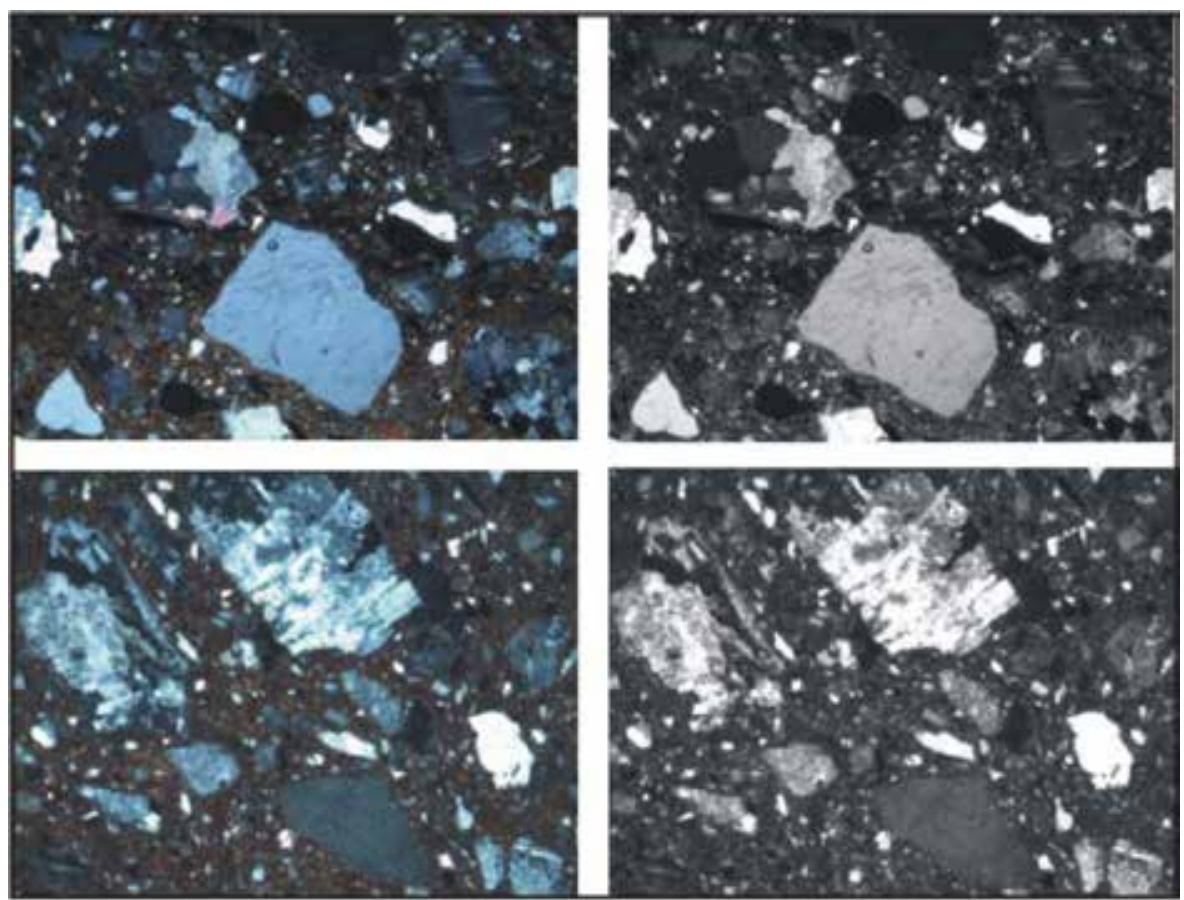

El agregado de tiesto molido plantea una situación diferente. Desde el punto de vista tecnológico su agregado intencional — como ocurre con la pizarra molida - se vincula con la obtención de paredes más resistentes. Sin embargo, deberíamos considerar que, si bien el tiesto molido genera vasijas más sólidas y longevas, quizá además del efecto tecnológico ese material tenga significados simbólicos. Algunos autores consideran que el agregado de tiesto molido es una manera de rememorar a los ancestros, lo que permitiría explicar en muchos casos su presencia en porcentajes bajos, careciendo de un efecto tecnológico apreciable. El uso de tiesto molido puede ser entendido entonces como una práctica que trasciende los aspectos meramente funcionales (Lemonnier, 1992; Gosselien, 1999) al evocar las antiguas vasijas y, de ese modo, su biografía y las relaciones sociales en las que estuvo involucrada la pieza (Puente, 2010: 465).

En los momentos agroalfareros tempranos del NOA no encontramos tiesto molido en las pastas de los estilos más representativos de los valles semiáridos y de la Puna. La única excepción es el estilo Vaquerías con una cantidad relativamente baja de este material pero que presenta similitudes morfológicas e iconográficas con el San Francisco Bicolor. Tal es así que Dougherty (1975) planteó que se trataba de un estilo derivado del San Francisco que había incorporado la policromía. Es evidente que el tiesto molido como atemperante no ha sido una elección para los alfareros de las otras subáreas del Noroeste de la Argentina como han revelado los estudios de pastas de la Tradición Tafí (Cremonte, 1996), del sur de los valles Calchaquíes (Pereyra Domingorena, 2010), del valle catamarqueño de Hualfín (Zagorodny y Balesta, 2005) y de Laguna Blanca (Espiro, 2012). Las cerámicas con agregado de tiesto molido están presentes en las tradiciones culturales de las tierras bajas sudamericanas (Prümers, 2002; Jaimes Betancourt, 2012; Saunaluoma y Schaan, 2012, entre otros) y son un rasgo recurrente de los conjuntos alfareros chaqueños (Lamenza et al., 2006). Tanto San Francisco como Angosto Chico Inciso se vincularían con algunas de estas tradiciones reflejando identidades y lugares de origen comunes.
Figura 14. Pastas con granito y cuarzo. Arriba: $\mathrm{ACH}$ (TUM 1 R5 C5 902). Abajo: SF PVo7 ocupación por debajo del basurero TUM1 B3. Izquierda: nicoles cruzados. Derecha: nicoles paralelos. 
Figura 15. Pastas con tiesto agregado. Arriba ACHI (Sitio Cucho de Ocloya OCLO M11). Abajo: SF (Sitio Pozo de la Chola PCHo1). Izquierda: nicoles Cruzados. Derecha: nicoles paralelos.
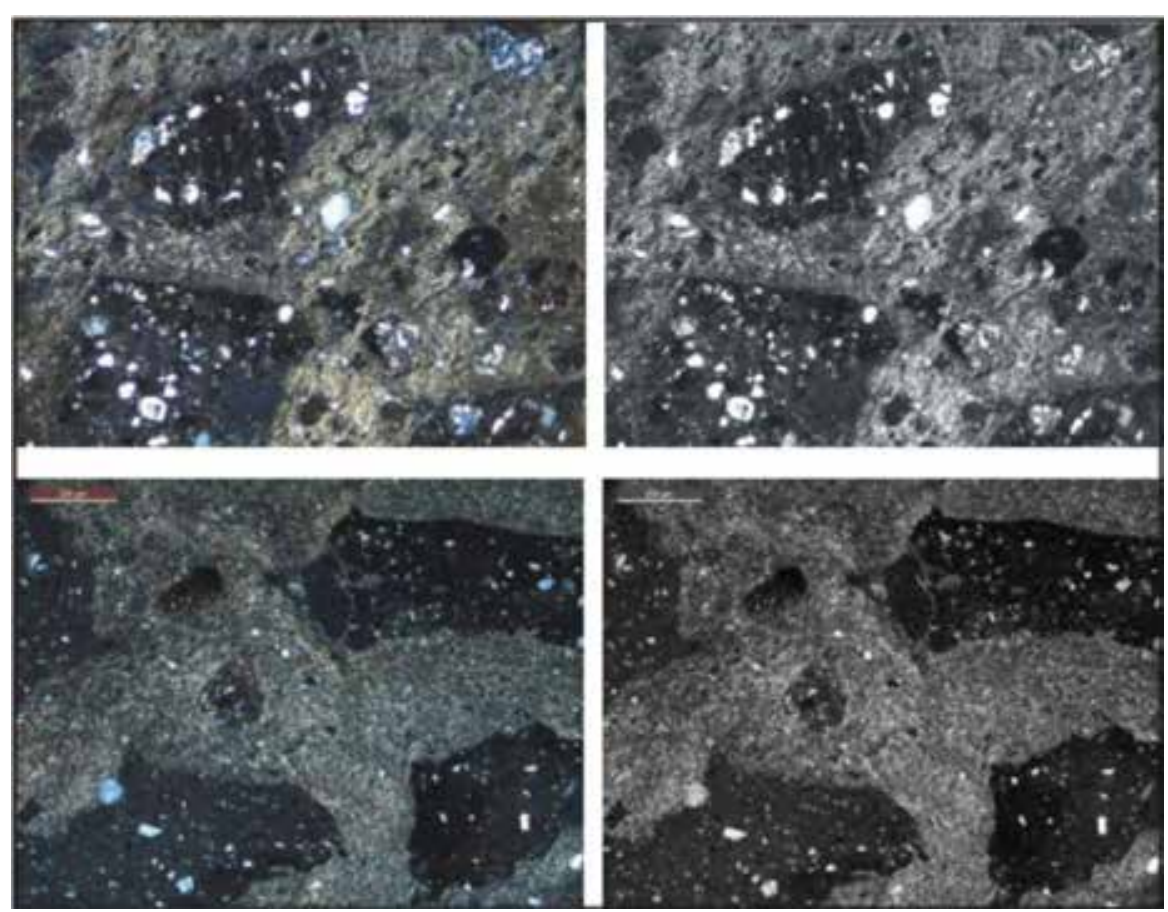

En la quebrada de Humahuaca, las vasijas ACHI están presentes desde aproximadamente mediados del siglo XIV (Nielsen, 2007: figura 2) siendo tanto de manufactura local como no local aunque con mayor abundancia de estas últimas, de acuerdo con los resultados logrados en este estudio. Durante el incario se evidencia un aumento significativo de ollas ACHI, y hemos registrado estrechas similitudes con las pastas de algunas vasijas Ordinarias, indicando la manufactura local de ambas. Esto estaría demostrando no solamente contactos más fluidos sino mayor integración de grupos del oriente con los quebradeños, quizás como resultado del traslado de contingentes (mitmaqkuna) o de otros vínculos sociales que implicaran corresidencias de quebradeños y yungueños. Procesos que habrían sido emulados y preservados en el marco de políticas económicas ejercidas por la administración estatal especialmente en el sector centro sur. Sobre la base de nuestros resultados, hemos identificado vasijas ACHI tanto de producción local como no local en los espacios quebradeños, con mayor presencia y permanencia en el sector más meridional. Una evidencia de esto último es que en la colección Gatto del Pucara de Volcán, el 25\% de las piezas (72 vasijas) son ACHI (Ottonello, 1994). Tendencias similares se han observado en los sitios AP1 ubicado en las yungas de Tiraxi (Garay de Fumagalli, 2003) y Santa Bárbara en Valle Grande (Madrazo, 1973). Asimismo, se advierte una integración y aceptación de esta materialidad en ámbitos domésticos y públicos. Entonces, y en relación con el período incaico podemos preguntarnos sobre la agencialidad del ACHI en la creación de un nuevo orden social generado por la anexión de estos territorios al incario.

Como señala Giddens, agencia es la capacidad de la gente de hacer cosas (1984) siendo cualidades de acción socialmente significativas (Dobres y Robb, 2000) que resultan en la creación de cultura material (Hegmon y Kulow, 2005). En este sentido, a partir del estudio de los objetos y de su relación con otros objetos, podríamos llegar a vislumbrar su agencialidad en las relaciones humanas, dado que las personas se socializan en mundos materiales (Gosden, 2005).

La evaluación de la variabilidad e interacción estilística a nivel regional considerando las elecciones tecnológicas como posibilidades prácticas que son revividas y seleccionadas a través de criterios culturales, nos permiten plantear algunas hipótesis de trabajo en relación con la agencialidad del estilo Angosto Chico Inciso en la interacción 
y/o integración entre grupos quebradeños y yungueños colindantes. Probablemente debamos entender la agencialidad del ACHI en su poder para conectar dos ambientes diferentes pero vinculados por su cercanía y por la presencia de accesos naturales directos: la Prepuna y los valles pedemontanos orientales. Para el caso de Tilcara, las vasijas ACHI han mostrado una conexión con Valle Grande, y para el caso de Tumbaya, con las yungas de Tiraxi y otros valles ubicados más al sur.

Los asentamientos del sector centro sur de la quebrada de Humahuaca (El Pobladito, Pucara de Volcán y Esquina de Huajra) se ubican en un ambiente de borde de prepuna, cercano a los valles orientales (menos de una jornada de marcha) contando con accesos directos con vegetación transicional y un relieve menos escarpado que en el sector central. Estas facilidades explicarían nexos más fluidos, intensos y duraderos entre las poblaciones de ambos pisos (Garay de Fumagalli, 2003, 2018). En este sentido no habría existido una oposición entre los valles semiáridos de la quebrada de Humahuaca y las yungas en el sentido de mundos antagónicos, sino como complementarios y contiguos. Estos nexos a través del hallazgo de abundante cerámica San Francisco en Volcán y en Raya Raya y, posteriormente ante una mayor representatividad del ACHI en la zona, nos lleva a pensar en una integración de los grupos yungueños y quebradeños en estas latitudes, por lo menos desde los inicios de la Era Cristiana. Más allá de los distintos procesos sociopolíticos acaecidos durante los Desarrollos Regionales e Incaico, dicha integración resultaría de un largo transitar y transmitir información entre los habitantes de ambos ambientes en el sentido de wayfaring, donde los lugares están delineados por movimientos en múltiples direcciones y no por los límites externos de esos movimientos (Ingold, 2011). Es en el marco de este contexto general que debemos comprender la yuxtaposición y perduración de identidades reflejadas en los modos de hacer la cultura material y, en nuestro caso, en la impronta de otras tradiciones tecnológicas como las expresadas en el Angosto Chico Inciso y San Francisco, sin que necesariamente exista una derivación directa del ACHI respecto del SF.

Es indudable el hiatus cronológico que separa a las últimas manifestaciones del San Francisco de las más tempranas del ACHI. Lamentablemente, carecemos de una base empírica sólida que permita proponer posibles escenarios sobre los procesos sociales acaecidos en ese lapso, quizás por un sesgo en las investigaciones arqueológicas en el extenso valle del río San Francisco, y también por la dificultad de llevarlas a cabo en los territorios que se prolongan hacia la llanura chaqueña. Ante este escenario real que nos enfrenta a la falta de contextos alfareros con fechados que cubran aunque más no sea un corto rango cronológico de ese hiatus, consideramos que la información aportada por las pastas puede ser una de las vías de contrastación de la hipótesis planteada por Ottonello (1994).

En las últimas décadas se han sumado evidencias interpretadas como el avance y ocupación de los valles orientales por parte de grupos de la quebrada de Humahuaca desde $c a .1000$ d. C. Los valles mencionados no parecen haber albergado importantes poblaciones estables Humahuaca en tiempos preincaicos. Por el contrario, durante la dominación incaica y como plantea Nielsen, se habría dado una "relocalización" de población Humahuaca para cumplir diferentes actividades. Esta situación es similar a la que habría ocurrido en la zona de Rodero, donde sitios muy tardíos y de ocupación breve están vinculados con prácticas agrícolas (Pucara del pie de la cuesta de Colanzulí, Juire, Putuquito y Papachacra en el valle de Yala-Cimarrones), reflejando el rol de estos valles en la producción agrícola, principalmente de maíz (Nielsen, 2001; Oliveto y Ventura, 2009).

Es innegable el impacto de las estrategias de control estatal en términos de las dinámicas sociales y su relación con la explotación económica de diversos ambientes. El incremento en la popularidad de las vasijas ACHI y Corrugadas, en ocasiones vinculado al 
consumo comunal de alimentos (como ha sido sugerido para el sitio AP1 de Tiraxi) (Cremonte y Garay de Fumagalli, 2013) o en enclaves como Santa Bárbara en Valle Grande (Madrazo, 1973: m.s); así como en eventos públicos auspiciados por la administración incaica como se plantea para el Pucara de Volcán (Cremonte y Scaro, 2010), darían cuenta de dichas estrategias. Sin embargo, estos grupos probablemente ya compartían territorios, historias y visiones culturales comunes conformando un sustratum sobre el cual se fueron diseñando distintos paisajes sociopolíticos en mayor o menor medida, delineados por tácticas de control ejercidas en tiempos preincaicos e incaicos.

Las pastas ACHI analizadas han mostrado la utilidad de las caracterizaciones petrográficas para conocer diferentes elecciones tecnológicas aplicadas en su manufactura. Si bien estas diferencias no son observables a simple vista, operan como un discurso oculto que refiere a probables tradiciones ancestrales (el uso del tiesto molido) y a lugares de producción mediante la identificación de materias primas accesibles a partir de las cuales podemos trazar rutas de interacción. Además, la ampliación de la muestra de pastas en secciones delgadas - tanto del ACHI como de otras modalidades alfareras- nos lleva a replantear el rol de la incidencia de vasijas ACHI de producción no local en el contexto la quebrada de Humahuaca.

Por último, debemos tener en cuenta que las variaciones registradas en el Angosto Chico Inciso permiten vislumbrar un mosaico de poblaciones pedemontanas, cuyas identidades y trayectorias de interacción con las poblaciones de distintos sectores de la quebrada de Humahuaca deberán ir definiéndose en la medida en que se profundicen los estudios arqueológicos y etnohistóricos.

\section{Agradecimientos}

Esta investigación se llevó a cabo en el marco de los Proyectos: CONICET PIP 0217Secter-UNJu 08/C 186 y ANPCYT PICT 2017-0280. Las secciones delgadas se confeccionaron en el taller de petrotomía del Instituto de Geología y Mineralogía de la UNJu. 


\section{Q Bibliografía}

" Arnold, D. E. (1985). Ceramic Theory and Cultural Process. Cambridge, Cambridge University Press.

»Bennett, W. C. (1948). Northwest Argentine Archaeology. En Archaeology, № 38. Yale University Publications.

"Cabrera, A. (1976). Regiones Fitogeográficas de la Argentina. En Enciclopedia Argentina de Agricultura y Jardinería, pp. 1-85. Buenos Aires, ACME.

»Casanova, E. (1942). El yacimiento arqueológico de Angosto Chico. En Relaciones de la Sociedad Argentina de Antropología, T3, pp.73-87. Buenos Aires.

》Cremonte, M. B. (1989). Informe PID-CONICET ms.

»----. (1990). Análisis de muestras cerámicas de la Quebrada de Humahuaca. En Avances en Arqueología, pp.1-7, 43. Tilcara.

»----. (1992). Algo más sobre el Pucara de Tilcara. Análisis de una muestra cerámica de superficie. En Cuadernos 3 pp. 1-27. San Salvador de Jujuy.

»----. (1994). Tendencias en relación a la producción y distribución de cerámicas arqueológicas en la Quebrada de Humahuaca. En Albeck, M. E. (ed.). Taller De Costa a Selva: Producción e Intercambio entre los pueblos agroalfareros de los Andes centro-sur, pp. 177-199. Tilcara, Instituto Interdisciplinario Tilcara, FFyL, UBA.

»----. (1996). Investigaciones arqueológicas en la Quebrada de La Ciénega, Dto. Tafí, Tucumán. Tesis Doctoral m.s. La Plata, Universidad Nacional de La Plata.

»----. (2006). El estudio de la cerámica en la reconstrucción de las historias locales. El sur de la Quebrada de Humahuaca (Jujuy, Argentina) durante los Desarrollos Regionales e Incaico. En Chungara 38 (2), pp. 239-247.

»Cremonte, M. B.; Solís, N. yL. Botto, L. (1999). Materias empleadas en la manufactura cerámica en la Quebrada de Humahuaca (Dto. Tilcara y Dto. Tumbaya. En Aschero, C. A.; Korstanje, M. A. y Botto, P. M. (eds.). En los tres reinos. Prácticas de Recolección en el cono Sur de América, pp. 15-26. San Miguel de Tucumán, Ediciones Magna.

»Cremonte M. B. y Garay de Fumagalli, M. (2001). Una ocupación temprana en el Pucara de Volcán (Dto Tumbaya, Jujuy). En Actas del XIII Congreso de Arqueología Argentina, Tomo 1, pp. 157-171. Córdoba.

»----. (2013) Diferentes modalidades de estructuración de la frontera suroriental Inka en el actual territorio de Jujuy. En Williams, V. y Cremonte, M. B. (eds.). Al Borde del Imperio, Paisaje Sociales, Materialidad y Memoria en áreas periféricas del Noroeste Argentino, pp. 57-74. Buenos Aires, Sociedad Argentina de Antropología.

»Cremonte, M. B. y Nieva, G. (2003). Registro y clasificación de las cerámicas del Basurero Tum1 B3 del Pukara de Volcán. En Cuadernos 20, pp. 373-391. San Salvador de Jujuy.

"Cremonte, M. B. y Scaro, A. (2010). Consumo de vasijas cerámicas en un contexto público del Pucara de Volcán (Dto. Tumbaya, Jujuy). En Revista de Arqueología y Etnología del MAE-USP 20, pp. 147-161.

»Cremonte, M. B.; Pereyra Domingorena, L. y Scaro, A. (2016). San Francisco, pastas cerámicas de una tradición alfarera de las yungas jujeñas. En Alconini, S. (ed.). Entre la vertiente tropical y los valles. Sociedades regionales e interacción prehispánica en los Andes centro-sur, pp. 241-261. La Paz, Plural. 
"Cremonte M. B. y Botto, E. I. (2016). Characterization of pottery fabrics from Cueva de Cristobal (Puna of Jujuy). En Stovel, E. y de la Fuente, G. (eds.). Vessels Explored: Applying Archaeometry to South American Ceramics and their Production, pp: 5-14. BAR British Archaeological Series.

" Curtois, L. (1976). Examen au microscope pétrographique des céramiques archéologiques. Notes et Monographies Techniques 8. CNRS.

»Debenedetti, S. (1910). Exploración arqueológica en los cementerios prehistóricos de La Isla de Tilcara. En Publicaciones de la Sección Antropología, Nº 6. Buenos Aires, FFyL, UBA.

»Dobres, M-A. y Robb, J. E. (2000). Agency in Archaeology. Londres/Nueva York, Routledge.

»Dougherty, B. (1975). Nuevos aportes al conocimiento del Complejo arqueológico San Francisco (Sector septentrional de las Selvas Occidentales. Subárea del Noroeste Argentino). Tesis Doctoral m.s. La Plata, Universidad Nacional de La Plata.

"Espiro, V. E. (2012). Del hacer de las ollas. La producción cerámica en una base residencial de la Aldea Piedra Negra (I milenio DC) Laguna Blanca. En Estudios Atacameños № 43 , pp. 53-70.

»Freestone, I. C. (1991): Extending Ceramic Petrology. En Middleton, A. y Freestone, I. (eds.). Recent Developments in Ceramic Petrology, pp.399-410, Occasional Paper № 81. Londres, British Museum.

»Garay de Fumagalli, M. (2003). Del formativo al inkaico, los valles Sudorientales de Jujuy en los procesos de interacción macroregionales. En Ortiz, G. y Ventura, B. (eds.). La mitad verde del mundo andino. Investigaciones Arqueológicas en la Vertiente Oriental de los Andes y las Tierras Bajas de Bolivia y Argentina, pp. 229-26o. San Salvador de Jujuy, Ediciones Ediunju.

"----. (2018). Fronteras de olvido. Poblaciones pre-hispánicas olvidadas del sudoriente de la Quebrada de Humahuaca, Jujuy, Argentina. En Cuadernos del Duende. San Salvador de Jujuy.

» Gatto, S. (1946). Exploraciones arqueológicas en el pucará de Volcán. En Revista del Museo de La Plata (Nueva Serie), sección Antropología, Tomo IV. La Plata

» Giddens, A. (1984). The Constitution of Society: Outline of the Theory of Structuration. University of California Press.

» González, A. R. (1977). Arte Precolombino de la Argentina. Buenos Aires, Filmediciones Valero.

» Gosden, Ch. (2005) . What Do Objects Want?. En Journal of Archaeological. Method and Theory, vol. 12, № 3 , pp. 193-211.

" Gosselain, O. (1999). In Pots We Trust. The Processing of Clay and Symbols in SubSaharan Africa. En Journal of Material Culture 4, pp. 205-230. Londres.

» Hammer, Ø.; Harper, D. y Ryan, P. (2001). PAST: Paleontological statistics software package for education and data analysis. En Paleontología Electrónica 4(1), 9.

» Hegmon, M y Kulow, S. (2005). Painting as Agency, Style as Structure: Innovations in Mimbres Pottery Designs From Southwest New Mexico. En Journal of Archaeological Method and Theory, vol. 12, № 4, pp. 313-334.

» Jaime Betancourt, C. (2012). Excavaciones de la Loma Salvatierra. Beni Bolivia-Plural.

»Ingold, T. (2011). Being Alive, Essays on Moment, Knowledge and Descriptions. Londres, Routledge. 
"Lamenza, G.; Balbarry, G.; Aguirre, B. y Calandra, H. (2006). Complejidad e Interacción de sociedades prehispánicas reseñas del Gran chaco Argentino. En Revista del XXVI Encuentro de Geohistoria Regional. Corrientes. CD-ROM.

» Letchman, H. (1977). Style in technology-some early thoughts. En Lechtman, H. y Merrill, R. (eds.). Material culture: styles, organization, and dynamics of technology, pp 3-20. Editions America West Publishers \& Distributors.

»Lemonnier, P. (1992). Elements of an Anthropology of Technology. Ann Harbor, Museum of Anthropology, University of Michigan.

» Madrazo, G. (1970). “El complejo estilístico. Angosto Chico Inciso”, en Revista ETNIA. №11:pp. 24-28. Olavarria. Buenos Aires.

» Madrazo, G. (1973). El yacimiento arqueológico de Santa Bárbara (Departamento de Valle Grande, Provincia de Jujuy). Investigación en un área de transición ambiental. m.s.

» Nielsen, A. E. (2001). Evolución Social en Quebrada de Humahuaca (AD 700-1536). En Berberián, E. y Nielsen, A. (eds.). Historia Argentina Prehispánica, Tomo 1, pp.171264:: Buenos Aires, Brujas.

»----. (2007). El Periodo de Desarrollos Regionales en la Quebrada de Humahuaca. Aspectos cronológicos. En Willians, V.; Ventura, B.; Callegari, A. y Yacobaccio, H. (eds.). Sociedades Precolombinas Surandinas, pp. 235-250. Buenos Aires.

» Nordenskiöld, E. (1903). Pracolumbische Whohn Und Begrabnisplatza An Der Sud-Wesgrenze von chaco. Kongl.SvenskaVetenskaps-AkademiensHandlingar". En Bandet 36, N $^{\circ}$ 7, pp. 1-22. Estocolmo.

»Oliveto, L. G. y Ventura, B. (2009). Dinámicas Poblacionales de los Valles Orientales del sur de Bolivia y norte de Argentina, siglos XV-XVII: Aportes etnohistóricos y arqueológicos. En Población y sociedad, 16(1), pp. 119-150.

» Ortiz, G. (2003). Estado actual del conocimiento del denominado Complejo o Tradición cultural San Francisco, a 100 años de su descubrimiento. En Ortiz, G. y Ventura, B. (eds.). La mitad verde del mundo andino. Investigaciones Arqueológicas en la Vertiente Oriental de los Andes y las Tierras Bajas de Argentina, pp. 23-72. San Salvador de Jujuy, Ediciones EdiUnju.

»Otero, C. (2013). Producción, usos y circulación de bienes en el Pucará de Tilcara. (Quebrada de Humahuaca, Jujuy). Tesis Doctoral. Buenos Aires, FFyL, UBA. Ms.

" Otero, C. y Cremonte, M. B. (2014). Local vessels technology of the Pucará of Tilcara during Inca Period (Quebrada of Humahuaca, Argentine). En Journal of Anthropological Archaeology 33, pp. 108-118.

»Ottonello, M. (1994). La cerámica Angosto Chico Inciso en el sitio del Volcán en el sector meridional de la Quebrada de Humahuaca. En Albeck, M. E. (ed.). Taller de Costa a Selva: Producción e Intercambio en los andes centro sur andinos, pp. 329-345. Tilcara, Instituto Interdisciplinario Tilcara, FFyL, UBA.

»Parodi, R. L. (1934). Las plantas indígenas no alimenticias cultivadas en la Argentina. En Revista Argentina de Agronomía 1(3), pp. 165-212. Buenos Aires.

»Pereyra Domingorena, L. (2010). Manufacturas alfareras de las sociedades aldeanas del primer milenio d. C. al sur de los Valles Calchaquíes. Tesis Doctoral. FFyL,UBA. M.s.

»Pereyra Domingorena L. y Cremonte, M. B. (2017). The Same Way of Doing Pottery. San Francisco Ceramic Fabrics from Tumbaya (Quebrada de Humahuaca) and San Pedro (San Francisco River Basin). En Scaro, A.; Otero, C. y Cremonte, M. B. (eds.). Pre-Inca and Inca Pottery. Quebrada de Humahuaca", pp 1-27. Suiza, Springer. 
»Prümers, H. (2002). Excavaciones arqueológicas en Pailón. En Pailó. Asentamiento prehispánico en el dto Santa Cruz, Bolivia. En Kava Band 22, pp. 99-213.

»Puente V. (2010). Prácticas de producción alfarera en el Valle del Bolsón (Belén, Catamarca.) Materias primas y modo de hacer CA 900-1600 d. C. Tesis Doctoral. FFyL, UBA. M.s.

》Quinn, P. S. (2013). Ceramic Petrography: The Interpretation of Archaeological Pottery \& Related Arte facts in Thin Section. Oxforf(UK), Archaeopress.

» Rye, O. S. (1981). Pottery Technolgy. Principles and Reconstruction. Manuals on Archaeology 4. Washington, Taraxacun.

»Salas, A. M. (1945). El antigal de Ciénaga Grande (Quebrada de Purmamarca, Prov. de Jujuy). Buenos Aires, Edición Del Museo Etnográfico, Serie A, V. FFyL, UBA.

"Saunaluoma, S. y Schaan, D. (2012). Monumentality in Western Amazonian formative Societies: geometrie ditched enclosures in the Brazilian state of Arce. En Antigua, vol. 2, e1.

"Scaro, A. (2015). Arqueología de Tumbaya. Paisajes sociales de un sector de la Quebrada de Humahuaca durante la Etapa Agroalfarera. Tesis Doctoral. Buenos Aires, FFyL, UBA. M. s.

»Scaro, A. y Cremonte, M. B. (2012). La vajilla de servicio de Esquina de Huajra (Dpto. Tumbaya, Jujuy, Argentina). Alternativas teóricas para interpretar su significado. En Revista del Museo de Antropología 5: pp. 9-22. Córdoba.

"Scaro, A y López Geronazzo, L. (2017). Contextual pottery and faunal analysis in the pre inka site El Pobladito. En Scaro, A.; Otero, C: y Cremonte, M. B. (eds.). Pre Inka and Inka Pottery. Quebrada de Humahuaca, pp 81-106. Suiza, Springer.

"Stoltman, J. B. (2001). The Role of Petrography in the Study of Archeological Ceramics. En Earth Sciences and Archaeology, pp. 297-326. Nueva York, Springer.

»Ventura, B. N. (1994). Un verde horizonte de sucesos. Taller de Costa a Selva. En Albeck, M. E. (ed.). Producción e intercambio entre los pueblos agroalfareros de los Andes Centro Sur), pp. 301-325. Tilcara.

» Zagorodny, N. y Balesta, B. (2005). Estudio multidimensional de la alfarería de La Ciénaga. En Sempé, C.; Salceda, S. y Maffia, M. (eds.). Presente y pasado de un pueblito catamarqueño, pp. 267-288. La Plata, Al Margen.

\section{María Beatriz Cremonte}

Doctora en Ciencias Naturales (UNLP) especializada en arqueología, estudios arqueométricos y tipológicos de cerámica, petrografía cerámica, paisajes sociales prehispánicos. Investigadora Principal en CONICET (Instituto de Ecorregiones Andinas, INECOA/CONICET/UNJu) y Profesora Titular Ordinaria de la cátedra Metodología y Técnicas de la Investigación Arqueológica (FHYCS- Universidad Nacional de Jujuy). Miembro titular del Consejo Directivo de INECOA (UNJu-CONICET) y del Consejo Directivo Interinstitucional del InDyA (Inst. de Datación y Arqueometría) como representante por CONICET. Ha publicado más de cien trabajos científicos en revistas nacionales e internacionales. 
1. Utilizamos el concepto de "yungas" como sinónimo de valles orientales. Los valles orientales de Jujuy han recibido distintas denominaciones, la primera (Parodi, 1934) fue Selva Subtropical Tucumano-Boliviana, luego fue denominada Provincia de yungas por Cabrera (1976); ambas clasificaciones están basadas en criterios fitogeográficos. Otras clasificaciones que asumieron criterios ecológicoculturales fueron las de Selvas Occidentales (González, 1977) y Región de las yungas (Ventura, 1994). 
